\title{
American foulbrood and its causative agent, \\ Paenibacillus larvae, in New Zealand's registered \\ hives and apiaries.
}

Samantha Amy Montrose Graham

\begin{abstract}
A thesis
submitted to the Victoria University of Wellington

in fulfilment of the requirements for the degree of

Master's of Science in Restoration Ecology
\end{abstract}

Victoria University of Wellington

Te Whare Wānanga o te Ūpoko o te Ika a Māui 



\section{Abstract}

Though the honey bee (Apis mellifera) is exposed to an extensive diversity of parasites and pathogens from multiple kingdoms, few are as devastating as American foulbrood. American foulbrood is a highly contagious bacterial disease, of which the causative agent (bacterium Paenibacillus larvae) infects honey bee brood through the ingestion of its spores, ultimately leading to the death of the infected larva and the collapse of the infected hive. Paenibacillus larvae's genotypes (ERIC I-IV) exhibit differing 'killing time' of infected larvae, resulting in different larval and colony level virulence of the disease within hives.

American foulbrood is found in New Zealand's registered hives, and poses a threat to the country's apiculture industry. The first objective of this thesis was to perform a genetic analysis on New Zealand's $P$. larvae field strains using the well-established methodology of rep-PCR with MBO REP1 primers. A total of 172 bacteria isolates were gathered from registered hives from 2011 to 2014 and examined. The MBO REP1 primer identifies the 'beta' genetic subgroups of $P$. larvae. By identifying beta subgroups, the ERIC genotypes that are present in New Zealand can also be concluded. The genetic analysis of $P$. larvae using rep-PCR is a first for New Zealand, and appears to be a first for Australasia. The second objective of this thesis was to conduct a temporal and geographical statistical analysis on American foulbrood infection rate trends in New Zealand's national and regional, divided into seven regions, registered hives and apiaries from 1994 to 2013.

The genetic analysis of $P$. larvae detected three 'beta' genotypic subgroups: $B, b$, and $Б$. From these findings it was concluded that ERIC I and ERIC II are present in 
New Zealand. Previous to my findings, subgroup $B$ and $B$ and ERIC II genotype had not been recorded outside of Europe. The statistical analysis reported that American foulbrood infection rates were significantly decreasing nationally. Results also reported that four of the seven regions' infection rates were significantly decreasing, whilst three regions were significantly increasing.

Conclusions on the subgroups and genotypes present in New Zealand gives the first insight to the virulence and occurrence of $P$. larvae strains. Additionally, the use of rep-PCR for the genetic analysis of $P$. larvae enables this thesis to contribute to the increasing knowledge on American foulbrood. By examining the temporal and geographic dynamics of American foulbrood, the results allow for the evaluation of current management strategies and the most recent understanding on the national and regional infection rates of the disease. 


\section{Acknowledgements}

"I will be a hummingbird; I will do the best I can"

- Wangari Maathai

Firstly, I would like to express my gratitude and thanks to my supervisor Phil Lester for his guidance and support. Thank you for giving me the opportunity and aiding me through this process, I have learnt and experienced so much. And to Postgraduates on Phil's 'Ant, Wasp and Bee' team thank you for your support and help, especially Alexandra Sebastien who answered my endless questions and was always willing to gave me her time. I would also like to thank Plant and Food Research Ltd for allowing me to use their facilities and samples; and the lovely people in the apiculture department who offered endless help, interest, and kindness to me.

Most importantly, I must thank my parents, Scott and Suzanne Graham. Mama and Dad you have sacrificed so much and given me everything and more. Your enduring love and encouragement has made me who I am today. Thank you for letting the little girl play with dinosaurs, read till her heart's content, and explore nature. I love you both very much and I hope I have made you proud of your eldest daughter.

I also would like to thank my two much-loved Nanas, Nana Pat and Nana Jan. You have both given me much laughter, love, and kind thoughts throughout this process. I would in particular like to thank Nana Jan, who has always shown me the world of knowledge. I will forever feel privileged, and hope it brings her joy, that I could do what she never had to opportunity to do in seeking higher education.

To my kind and patient Benjamin, words cannot encompass the years of unwavering love and support you have given me. Together we have celebrated each other's tribulations and joys of the university process. I can't wait to share the next stage of our journey together.

And to Ed, your wagging tail and daily walks always put a smile on my face and got me off my desk. 


\section{Table of Contents}

Abstract

Acknowledgements iii

Table of Contents iv

List of Figures vi

List of Tables

Chapter One 1

Introduction $\quad$................................................. 1

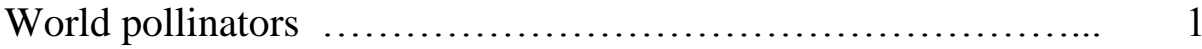

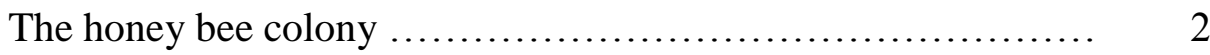

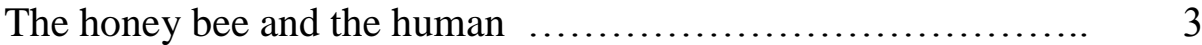

Honey bee disease transmission $\ldots \ldots \ldots \ldots \ldots \ldots \ldots \ldots \ldots \ldots \ldots \ldots \ldots, \quad 5$

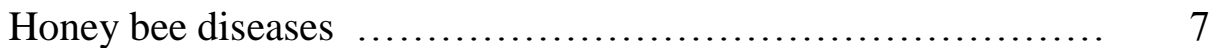

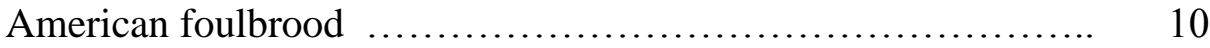

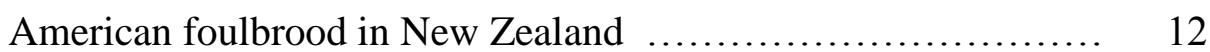

Genetic classification and identification of Paenibacillus larvae ... 16

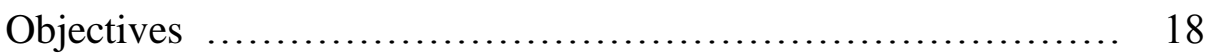

$\begin{array}{lr}\text { Chapter Two } & 20\end{array}$

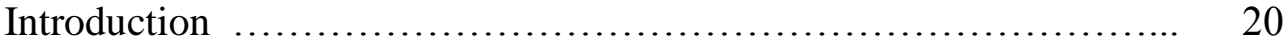

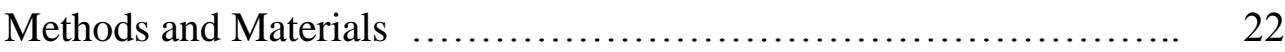

Genetic analysis of Paenibacillus larvae ....................... 22

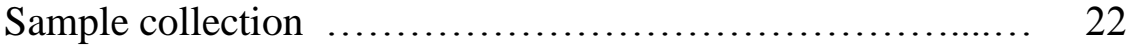

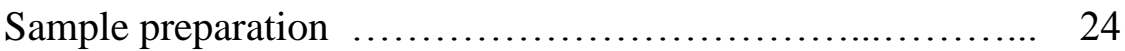

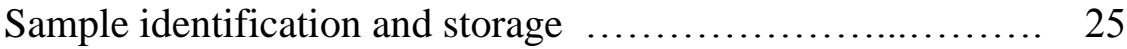

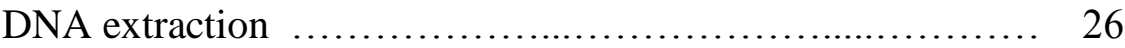

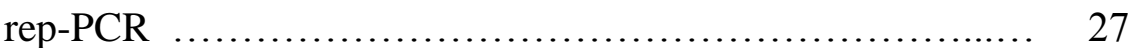

Statistical analysis of American foulbrood historic data .......... 29 


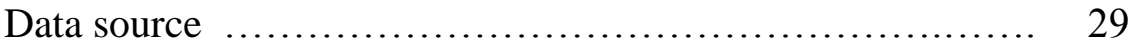

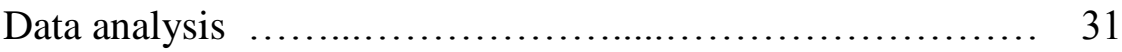

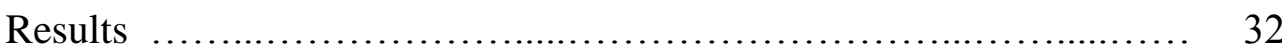

Genetic analysis of Paenibacillus larvae ......................... 32

Statistical analysis of American foulbrood historic data ......... 35

Registered hives, apiaries, and beekeepers trends $\ldots \ldots \ldots \ldots . \quad 35$

American foulbrood infections in New Zealand registered

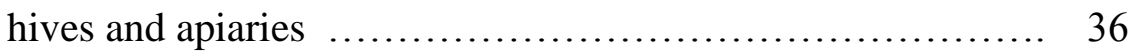

American foulbrood infections in regional registered hives .... 40

American foulbrood infections in regional registered apiaries .. 42

Seasonal trends of American foulbrood infection rates ......... 44

$\begin{array}{ll}\text { Chapter Three } & 45\end{array}$

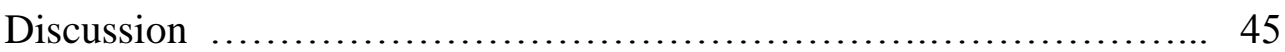

$\begin{array}{lr}\text { Bibliography } & 58\end{array}$

$\begin{array}{lr}\text { Appendix } & 69\end{array}$

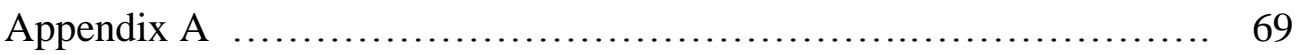




\section{List of Figures}

\section{Chapter Two}

2.1: The seven regions of New Zealand

2.2: Three-day-old $P$. larvae colony growth on Oxoid Brain Heart infusion agar ......

2.3: The rep-PCR fingerprinting of $P$. larvae from New Zealand field isolates .. 28

2.4: The regional variance in the frequency and occurrences of P. larvae subgroups

2.5: The trends in New Zealand's registered hive, apiary, and beekeeper numbers

2.6: The American foulbrood infection in national and regional registered hives 1994 to 2013

2.7 The American foulbrood infection in national and regional registered apiaries 1994 to 2013 39

2.8: The monthly trends of American foulbrood reports 44

\section{List of Tables}

\section{Chapter One}

1.1: Categorisation of $P$. larvae's genetic subgroups in ERIC genotypes

\section{Chapter Two}

2.1: The geographic boundaries encompassed within the seven regions of New Zealand

2.2: Individual banding patterns for P. larvae's four genetic subgroups $B, b, \beta$, and $\bar{B}$ 28

2.3: The regions from which the $P$. larvae isolates originated

2.4: The occurrence of $P$. larvae subgroups $B, b$, and $E$ in six regions of New Zealand 


\section{CHAPTER ONE}

\section{Introduction}

\section{World pollinators}

The relationship between pollinators and angiosperms (flowering plants) is critical to sustaining healthy agricultural and natural ecosystems (Calderone, 2012a). Pollinator species from multiple classes perform pollination services to over $80 \%$ of angiosperm species (Calderone, 2012a). The mutualistically beneficial relationship between pollinator and plant facilitates the plant's sexual reproduction while providing nectar, a food source, to the pollinator. In the absence of pollinators, angiosperms' fruit development is substantially compromised (Calderone, 2012a).

Primarily driven by flower morphology, the evolutionary selection pressures on the plant-pollinator relationship have lead to bifurcation of pollinators into specialised or generalised (Campbell, 2008; Klein et al., 2007). An example of a specialised pollinator is seen with the hummingbird (Trochilidae). The hummingbird, with its specialised elongated beak and tongue, is the only species able to pollinate the deep tubular flowers of the crimson beebalm (Monarda didyma) (Campbell, 2008). Conversely, generalist pollinators exhibit 'plant choice flexibility' during foraging. This behaviour is most commonly recorded among insects (Campbell, 2008; Klein et al., 2007).

The versatility in flower selection behaviours has allowed the agricultural industry to become reliant on insect pollinators. Approximately $84 \%$ of animal-pollinated crops are insect pollinated, generating US\$215 billion worldwide annually (Le Conte \& Navajas, 2008; vanEnglesdorp \& Meixner, 2010). The significance of insect pollination services to 
global food production is rising. An example of this is seen with the agricultural sector's reliance on pollinators increasing by 50-62\% from 1961 to 2004 (vanEnglesdorp \& Meixner, 2010).

Of the agricultural insect pollinators, the generalist western honey bee Apis mellifera (also known as the European honey bee) is the most economically important (Le Conte \& Navajas, 2008). The honey bee's pollination services increase animal-pollinated crop yield by $96 \%$, with $45 \%$ of leading food commodities reliant on its services (Potts et al., 2010; vanEnglesdorp \& Meixner, 2010). Attributing to the pollination efficiency of Apis mellifera is its 'crop constancy' behaviour, or the behaviour of consistently visiting one plant species at a time (Genersch, 2010a). Considered the "most important productive livestock" (Genersch, 2010a), the honey bee is now the primary pollinator of agricultural crops (Le Conte \& Navajas, 2008; Klein et al., 2007).

\section{The honey bee colony}

The classification of eusocial (highly social) insects is based on the division of labour, mutual care of brood, and sterile workers. Within insect species, this rare social structure has proven to be extremely successful (Amdam et al., 2004). The honey bee is a prime example of a successful eusocial insect, with its hierarchical caste divisions, elasticity in labour division, and cooperative broodcare (Amdam et al., 2004).

The honey bee has three caste divisions: the reproducing queen, the sterile female workers, and the drones (males) (Matherson \& Reid, 2011; Winston, 1987). Honey bees exhibit the four holometabolous life stages (full metamorphosis) of an egg, larvae, pupa, and adult stage. The length of each stage is dependent on the caste and gender of the individual bee (Matherson \& Reid, 2011). The caste with the shortest length for complete 
metamorphism is the queen (16 days), followed by the worker (21 days), with the drone exhibiting the longest development length (24 days) (Matherson \& Reid, 2011).

The colony structure comprises primarily of tens of thousands of the related female workers, who form the division of labour; the brood; and the one reproducing queen. The cooperation and complex social interactions between the workers enable the colony opportunities for optimum health, growth, and development (Evans \& Schwarz, 2011). The mechanism 'temporal polyethism', or the allocation of age-based labour between sterile workers, is the main catalyst in the maintenance and development of the hive (Huang \& Robinson, 1996). There is, however, plasticity within workers, with the workers' labour allocation able to change depending on the colony's requirements and conditions (Matherson \& Reid, 2011; Huang \& Robinson, 1996).

\section{The honey bee and the human}

Originating in Africa, Europe, and Asia, the western honey bee is now naturalised worldwide (Butz Huryn, 1997). The expansion of the honey bee's range is primarily accredited to its value to humans, with domesticated colonies being transported alongside human migrations and colonisations (Huryn, 1997; vanEnglesdorp \& Meixner, 2010).

In modern beekeeping, individual honey bee colonies are managed within individual artificial hives. The hive is separated into distinct sections to cater for different functions (Matherson \& Reid, 2011). For example, the separation of the honeycomb section and the broodcomb section within the hive allows for brood to be kept isolated from the stored honey. An apiary, the location that hives are kept, may hold one or more hives (Matherson \& Reid, 2011). 
The value of the honey bee to humans has maintained its significance, with the utilisation of colonies continuing into the $21^{\text {st }}$ century. Hive products, such as honey and wax, continue to remain a desirable commodity, with honey's global worth valued annually at US\$1.25 billion (vanEnglesdorp \& Meixner, 2010). However, the value of A. mellifera is substantially attributed to pollination services, which assist in sustaining global food production (Genersch, 2010b; vanEnglesdorp \& Meixner, 2010).

Similar to other domesticated animals, honey bees have undergone 'selective breeding', or traits desirable to humans being selected through arranged breeding. An example of this is demonsrated in the selecting for a placid temperament in managed honey bees to minimises the potential threat of worker aggression towards beekeepers (Vogel, 1871). An additional example is beekeepers selecting for a higher annual honey yield. A study showed that within five years of selecting for higher honey yields honey storage increased by $15.9 \%$ (GuzmanNovoa \& Page, 1999). Managed hives are now able to produce over $150 \mathrm{~kg}$ of honey annually (Guzman-Novoa \& Page, 1999; Donovan, 1980).

Understanding the selective breeding of honey bees gives a brief insight to the shifting demands and values of humans towards the honey bee. Currently, beekeepers are addressing a new principal concern in beekeeping, honey bee diseases. Diseases frequently lead to a shortening of life spans, a decrease in sperm productivity, an increased risk of contracting further diseases, and a decrease in body reserves in honey bees (Currie \& Tahmasbi, 2008). With such an investment in hives through agricultural pollination and hive products, there is a demand for the overall health and prosperity of colonies.

The effect of diseases and the demand for hive health has led to selective breeding for genetic and behavioural traits that encourage the honey bee's resistance to diseases (Currie \& Tahmasbi, 2008; Danka et al., 2012). Selectively breeding for more resilient honey bees may 
also be in response to the repercussions of using chemicals as a long-term method for disease control. Chemical treatment for diseases can lead to increased costs in hive management, contaminated hive products, and resistance development of the disease to the chemicals (Rinderer et al., 2014). The varroa mite (Varroa destructor) has substantially affected honey bee colonies worldwide and is showing resistance to chemical treatment (Sammataro et al., 2000). This has lead to breeding programmes selecting for 'Varroa sensitive hygiene' behaviours. Studies show that hygienic behaviours such as self-grooming (autogrooming) and group grooming (allogrooming) are the most effective defence mechanisms for mite removal (Currie \& Tahmasbi, 2008; Ibrahim et al., 2007; Rinderer et al., 2014).

\section{Honey bee disease transmission}

Honey bee disease transmission routes bifurcate into vertical and horizontal transmission. Vertical transmission, or the transmission route of a disease from the queen to the lower castes, is deemed to have greater manageability by beekeepers compared with horizontal transmission (Evans \& Schwarz, 2011). However, horizontal transmission, or the transmission route of a disease between individuals of the same caste, is the most common transmission route (Evans \& Schwarz, 2011).

The spread of honey bee diseases is facilitated both by honey bee behaviours and management practises. The honey bees' eusocial behaviours provide benefits to the colony such as sustained growth and longevity. However, the eusocial behaviours of dense living conditions, sharing amongst nest-mates, and crossovers with neighbouring colonies, enhances the opportunities for the spread of diseases (Berenyi et al., 2006). Disease spread is also facilitated by honey bee management practises, with the uniformed spacing of managed hives within apiaries promoting the spread of diseases between hives by increasing interactions and crossovers with neighbouring colonies (Lindstrom et al., 2008b). Poor 
management is a transmission route for the honey bee disease American foulbrood (bacterium Paenibacillus larvae), with the use of infected equipment and the movement of infected hives into healthy apiaries greatly facilitating the spread of the disease (Berenyi et al., 2006; Genersch, 2008).

The holometabolous life cycle of honey bees presents distinctive niche opportunities for disease infections, with some diseases exclusively infecting specific development stages (Evans \& Schwarz, 2011). For example, the bacterial diseases American foulbrood and European foulbrood (bacterium Melissococcus plutonius) solely infect the larval and pupal development stages, while the parasitic tracheal mite (Acarapis woodi) infects only the adult stage (Evans \& Schwarz, 2011; Donovan, 1980; Sammataro et al., 2000). Diseases can also infect multiple development stages, for instance the sacbrood virus can infect the honey bee's larval, pupal, and adult stages (Chen et al., 2004).

Honey bees exhibit colony and individual level behaviours that provide resistance to diseases (Evans \& Spivak, 2010). 'Social immunity' is the collective colony resistance to diseases, employed through the cooperative behaviours of workers (Evans \& Spivak, 2010). Social immunity is demonstrated through the use of allogrooming, where workers remove and discard foreign bodies and pathogens from nest-mates. Allogrooming is successfully employed by the Asian honey bee (Apis cerana) for the removal of varroa mites (Evans \& Spivak, 2010). Autogrooming is another form of resistance behaviour, with individual bees removing foreign pathogens, such as tracheal mite, from themselves (Evans \& Spivak, 2010). Both of these behaviours reduce the spread of parasites and diseases within the hive (Evans \& Spivak, 2010).

The utilisation of hygienic behaviours as a resistance mechanism to diseases can be disadvantageous to the honey bee. The nurse bee's hygienic behaviours successfully reduce 
the spread of European foulbrood within a hive. However, these same behaviours enhance the spread of American foulbrood (Forsgren, 2010; Genersch, 2010a). In attempt to rid the hive of American foulbrood, the nurse bee removes infected larvae and cleans the brood cells (Genersch, 2010a). By doing so, the nurse bee becomes contaminated with the disease, spreading it throughout the hive and infecting healthy larvae (Evans \& Spivak, 2010; Genersch, 2010a).

\section{Honey bee diseases}

Globally, managed honey bee colony numbers have risen over the last fifty years. This is accredited to the expansion of beekeeping in developing nations and the technique of splitting hives to replace colony losses (vanEnglesdorp \& Meixner, 2010). In contrast, other regions have recorded a mass decline in honey bee populations (Becher et al., 2013; vanEnglesdorp \& Meixner, 2010). The decline has been centred primarily to Europe and America, which have recorded a loss of $26.5 \%$ and $49.5 \%$ of colonies respectively from 1961 to 2007 (vanEnglesdorp \& Meixner, 2010). The mass decline of honey bee populations has been categorised under the term 'Colony Collapse Disorder' (CCD) (Genersch et al., 2009). CCD is recognised by its distinct symptoms such as the mass loss of workers from apparently healthy hives, the lack of dead bees within and outside hives, and a lack of robbing of the weakened hive. The enigmatic condition of CCD has generated international interest and concern towards honey bee health, and directed attention to the 'global pollinator crisis' debate (Genersch et al., 2009; Neumann \& Carreck, 2010). CCD is just one of the many devastating diseases that affect the honey bee's overall health and prosperity. The worldwide naturalisation and globalisation of $A$. mellifera has exposed the honey bee to an extensive diversity of parasites and pathogens from multiple kingdoms (vanEnglesdorp 
\& Meixner, 2010). Furthermore, diseases are found to be host switching to A. mellifera, this has been reported with the varroa mite.

The varroa mite, once exclusively parasitic to the Asian bee, first switched hosts to the western honey bee in 1963 (Goodwin \& Van Eaton, 2001; vanEnglesdorp \& Meixner, 2010). It now populates most regions that manage honey bees. The female mite and her offspring feed off the honey bee's hemolymph, resulting in colony collapse by means of severe malnutrition and deformity of infected bees (vanEnglesdorp \& Meixner, 2010; Todd et al., 2007; Le Conte \& Navajas, 2008). It has also been reported that varroa mites are transmission vectors for honey bee viruses (vanEnglesdorp \& Meixner, 2010). Virus transmission from the varroa mite to the honey bee may occur directly into the honey bee's haemolymph or through the opportunities caused by the mite's infection, such weakening of the honey bee's immune system (vanEnglesdorp \& Meixner, 2010). The Deformed wing virus (DWV) and Acute bee paralysis virus (ABPV) infection rate show a positive correlation with colony mite load (vanEnglesdorp \& Meixner, 2010). Potential links have also been reported between varroa infections and the Kashmir bee virus (KBV) (vanEnglesdorp \& Meixner, 2010). Studies show that KBV and ABPV infections are harmless to honey bees until artificially injected into the hemolymph, in which the viruses become lethal (Todd et al., 2007; Chen et al., 2004). Introducted in 2000, the varroa mite is now established throughout New Zealand, and is ascribed to the $16 \%$ loss reported in North Island colonies and the almost total loss of feral colonies (Todd et al., 2007; Zhang, 2000; Mondet et al., 2014).

The honey bee is host to at least 18 viruses. Kashmir bee virus, Acute bee paralysis virus, black queen cell virus (BQCV) and sacbrood virus (SBV) are recorded as the most common viruses infecting managed hives (Chen et al., 2004). Research suggests that Israeli acute 
paralysis virus (IAPV) is linked to the mass colony losses in America and Europe (vanEnglesdorp \& Meixner, 2010). Yet, as there is shared genetic relationship between $\mathrm{ABPV}, \mathrm{KBV}$, and IAPV there is possibility for misclassification (vanEnglesdorp \& Meixner, 2010). Honey bee viruses infect the honey bee at various development stages. For example, DWV and KBV infect the larval, pupal and adult stages of the honey bee whilst ABPV solely infects the adult stage (Chen et al., 2004).

Nosema apis and Nosema cerana are microspordia (or fungal protozoa) species that infect honey bees (Klee et al., 2007). Separation between $N$. apis and N. cerana is achieved by molecular analysis involving $16 \mathrm{~S}$ rRNA gene sequences, as morphologically the fungi are indistinguishable (Klee et al., 2007). Similarly to the varroa mite, N. cerana has switched hosts from the Asian honey bee to the western honey bee. $N$. cerana was first reported in western honey bee hives in America in 1995, then in Europe in 1998 (vanEnglesdorp \& Meixner, 2010). In laboratory studies, $N$. cerana infections demonstrated a higher virulence in the western honey bee than N. apis (Le Conte \& Navajas, 2008; vanEnglesdorp \& Meixner, 2010). These findings are supported in field studies, with Spain reporting a greater loss of $N$. cerana infected colonies than N. apis infected colonies (Le Conte \& Navajas, 2008; vanEnglesdorp \& Meixner, 2010). The fungus is spread by horizontal transmission, infecting the adult bee's midgut through the ingestion of Nosema spores (vanEnglesdorp \& Meixner, 2010; Le Conte \& Navajas, 2008). Nosema infection causes inflammation and damage to the epithelial cells, leading to death of the infected individual and colony collapse (vanEnglesdorp \& Meixner, 2010; Le Conte \& Navajas, 2008). Consequences of Nosema infections have prompted it to be labelled as an economically significant disease (vanEnglesdorp \& Meixner, 2010). N. apis and N. cerana have both been reported in New Zealand's managed hives (Klee et al., 2007). 
Honey bees are susceptible to two bacterial brood diseases, American foulbrood and European foulbrood (vanEnglesdorp \& Meixner, 2010). American foulbrood is considered a greater threat to honey bee hives than European foulbrood, due to European foulbrood's lower morality rate (Genersch, 2010a; Forsgren, 2010). While European foulbrood has not been reported within New Zealand (Forsgren, 2010), American foulbrood is regarded as one of the most devastating diseases to New Zealand's honey bees (Goodwin, 2006).

\section{American foulbrood}

American foulbrood (AFB) is a widely distributed, highly contagious bacterial disease that infects the honey bee's larval and pupal stages (Genersch, 2008; Lindstrom et al., 2008b). American foulbrood is considered to be one of the most consequential and severe diseases affecting honey bees, and one of the few diseases that causes complete collapse of the infected colony (Alippi et al., 2004; Genersch, 2010b; Lindstrom et al., 2008a). 'Foulbrood' was first described in the $18^{\text {th }}$ century to give characterisation to a honey bee disease that produced a foul odour. In the $20^{\text {th }}$ century 'Foulbrood' was differentiated into two diseases, American foulbrood and European foulbrood (Forsgren, 2010; Genersch, 2008). Unlike European foulbrood, the only other bacterial honey bee brood disease, American foulbrood is lethal to all larvae infected (Forsgren, 2010; Alippi et al., 2002). Due to the ultimate death of infected larvae and colony collapse, American foulbrood is significantly impacting the apiculture industry worldwide (Genersch et al., 2005; Lindstrom, 2008).

The causative agent of American foulbrood is the rod-shaped $(2.5-5 \mu \mathrm{m}$ by $0.5-0.8 \mu \mathrm{m})$, Gram-positive, spore-forming bacterium Paenibacillus larvae (Alippi et al., 2002; Forsgren, 2010). Larvae are most susceptible to American foulbrood between 12-36 hours after hatching, with infection occurring through the ingestion of P. larvae spores (Genersch et al., 
2005). Studies differ on the number of spores needed to be ingested for infection to occur, with arguments from 10 spores through to 'large numbers' (Genersch, 2010; Lindstrom et al., 2008a; Genersch et al., 2005). Fluorescence in situ hybridisation has shown that spores, once ingested, germinate into vegetative rods and proliferate within the larvae's midgut. This proliferation leads to damage of the larvae's epithelium and ultimately death by possible starvation or bacterial invasion of the haemocoel (Genersch, 2010; Genersch, 2008; Poppinga et al., 2012). Upon the larvae's death, the decaying tissue resembles a brown, semi-fluid, 'ropy' mass. The ropy stage is followed by the 'foulbrood scale' stage, in which the tissue becomes 'glued' to the brood cell wall causing a hardened scale (Genersch, 2010a; Genersch et al., 2005). The ropy and foulbrood scale stage are visual characteristics for the diagnosing of American foulbrood (Goodwin, 2006). Once the bacteria have consumed the larva's tissue, the vegetative rods produce spores. A deceased larva in the foulbrood scale stage is capable of containing millions of infectious spores (Genersch, 2010a; Genersch et al., 2005).

Although a brood disease, adult workers bees can become contaminated with American foulbrood (Genersch, 2010a; Lindstrom et al., 2008a). Contamination of a worker occurs by the transferral of spores directly from the deceased larva's infected tissue to the worker or from interactions with other contaminated workers (Genersch, 2010a; Lindstrom et al., 2008a). Contaminated workers, whilst they cannot be infected with the disease, are able to transmit American foulbrood to healthy brood (Lindstrom, 2008). A hive with contaminated workers can possess a high spore density without displaying the clinical symptoms of the disease (Lindstrom et al., 2008b).

Paenibacillus larvae spores exhibit a high resistance to chemicals and heat with the ability to survive extreme environmental conditions and 35 years without contact with its 
host (Genersch, 2010a). The durability and resilience of $P$. larvae spores present limitations and unique dilemmas to the risk assessment and control of American foulbrood (Genersch, 2010a; Ryba et al., 2012). There is no effective long-term control for American foulbrood; with the control method for many countries is the applying of antibiotics (Ryba et al., 2012). While antibiotics suppress the symptoms by targeting the $P$. larvae vegetative cells, the nontargeted spores are able to remain and accumulate within the hive, contaminating the honey, workers, and the surrounding area (Alippi et al., 2004; Genersch \& Otten, 2003). Moreover, the long-term implemention of the antibiotic oxytetracycline, has lead to infected hives developing resistance to the chemical in North and South America (Alippi \& Reynaldi, 2006). In New Zealand antibiotics are banned as a method of American foulbrood control. New Zealand law instead demands the burning of infected hives and the disinfecting of contaminated equipment (Alippi et al., 2002; Genersch, 2008).

\section{American foulbrood in New Zealand}

Honey bees were introduced to New Zealand in 1839 from Europe with additional imports from America and Britain (Palmer-Jones, 1964; Huryn, 1997). Beekeeping is now one of New Zealand's most important primary industries, producing pollination services and internationally renowned hive products, such as Manuka honey (Matherson \& Reid, 2011). New Zealand's honey bee pollination services, hive products, and live exports have an estimated annual value of NZ\$5.1 billion, with honey exports alone valuing at NZ\$81 million annually (NBA, 2011). The introduced honey bee also provides pollination to 10$15 \%$ of New Zealand's native flowering taxa (Huryn, 1997). In 1906, the first national census of beekeepers and hives was published, recording 15,396 beekeepers and 74,341 hives. The registration of hives became compulsory under the Apiaries Amendment Act in 1913 (Matherson \& Reid, 2011). More recently, the Biosecurity Order, legislated in 1998, 
states that all apiary locations must be registered (Matherson \& Reid, 2011; Biosecurity Order, 1998). In mid 2014, 4,814 beekeepers, 30,668 apiaries, and 507,247 hives were registered in New Zealand.

In 1877, 38 years after the initial introduction of honey bees to New Zealand, the first incidences of American foulbrood were reported in managed hives (Palmer-Jones, 1964). Ten years later American foulbrood was reported throughout the country and accredited for the 70\% drop in honey production (MAF, 2008; Palmer- Jones, 1964; Goodwin, 2006). The Apiaries Act, legislated in 1924, banned the importation of honey bees, used equipment and hives into New Zealand to limit the spread of American foulbrood (Donovan, 1980). Government-led hive inspections during 1947 led to the first reliable report on the prevalence of American foulbrood in New Zealand hives. The report showed that of the 74\% registered hives inspected, $1.7 \%$ were detected as being infected with American foulbrood (Goodwin, 2006). In 1950, the government-led hive inspections were held again. Of the 78\% registered hives inspected, 2.02\% were detected as being infected with American foulbrood (Goodwin, 2006). In 1961, the reports of American foulbrood in managed hives had fallen to $0.23 \%$. This decline was attributed to the banning of 'shook swarming', where bees are shaken from an infected hive to an empty hive, and the implementing of the new control methods (Goodwin, 2006). Goodwin's (2006) review of American foulbrood infection rates in New Zealand hives were reported to have fluctuated during the 1960 s to the early 1980s, with between $0.23 \%$ and $0.8 \%$ hives being reported as infected. In 1990, hive infection rates peaked at $1.2 \%$. Infection rates gradually declined to $0.38 \%$ in 1998 , and finally fluctuating between $0.31 \%$ and $0.26 \%$ from 1999 to 2006 (Goodwin, 2006).

In 1993, Goodwin et al. (1994) found that $12.5 \%$ of hives owned by beekeepers that manage fewer than 50 hives were infected with American foulbrood. The disparity between 
the percentage of infected hives by those beekeepers who kept fewer than 50 hives $(12.5 \%$ of hives infected) and the overall hive infection for New Zealand ( $0.9 \%$ of hives infected) provides a potential insight to the relationship between beekeeping and honey bee diseases. One reason for this disparity could be that beekeepers that manage over 50 hives may be professional beekeepers with greater skill at noticing the symptoms of American foulbrood and therefore report it. With potentially those who managed fewer than 50 hives being hobbyists, and lacking the skills needed for diagnosing American foulbrood. This theory requires further study but with the increasing number of hobbyists, especially in urban spaces, understanding the levels in the ability to diagnose diseases could be beneficial (Arena, 2010). New Zealand has seemingly begun to account for the difference in diagnosing abilities, with laws stating that a certified American foulbrood inspector must inspect hives once a year (Biosecurity Order, 1998).

Changes in American foulbrood control methods were introduced by the Department of Agriculture in 1950 (Goodwin, 2006). Shook swarming and other methods of disease control were replaced with the control method of burning diseased hives and sterilisation of infected equipment (Goodwin, 2006). Infected hives are diagnosed by the beekeeper or by a certified inspector, through recognising the visual symptoms of American foulbrood (Genersch, 2008; Goodwin, 2006; Biosecurity Order, 1998). The standard test for American foulbrood is the 'ropiness test'. The ropiness test is when a matchstick is inserted into the suspected diseased larva or pupa, and when the matchstick is drawn out if the tissue stretches then snaps it is consider a sign of infection (Matherson \& Reid, 2011). Samples of suspected diseased hives can also be voluntarily sent to registered laboratories for the diagnosis of American foulbrood. For laboratory analysis, adult bee, larvae, brood comb, honey, or frames are sent for spore identification using microscope analysis or bacteria cultivation on agar plates (Goodwin, 2006). 
Since 1991, the National Beekeepers' Association of New Zealand Inc (NBA) under the American foulbrood National Pest Management Strategy (AFB NPMS) has managed the control of American foulbrood in New Zealand. The aim of the AFB NPMS is the elimination of American foulbrood from New Zealand (Goodwin, 2006). In 2008, the strategy's aim to reduce American foulbrood incidences to $0.1 \%$ was considered unsuccessful (MAF, 2008). The introduction of varroa mite (Varroa destructor) into New Zealand in 2000 was given as a potential explanation for the lack of decline in American foulbrood numbers, as honey bee disease control and awareness was primarily directed towards the mite (Todd et al., 2007; MAF, 2008). A further explanation given was the possibility of under-reporting of infected hives leading to incorrect practises in American foulbrood control (MAF, 2008).

American foulbrood is a major and devastating disease to honey bees in New Zealand, with significant economic loss incurred due to the disease and its control (Alippi et al., 2004). Furthermore, as the spores are able to spread via contaminated honey, there may be severe repercussions for New Zealand's highly valued honey exports in the future (Alippi et al., 2004; Lindstrom et al., 2008a).

\section{Genetic classification and identification of Paenibacillus larvae}

The scientific classification of Paenibacillus larvae has undergone multiple linage restructures in response to $16 \mathrm{~S}$ rRNA sequencing and strain analysis. This has lead to $P$. larvae being a branch away from the original Bacillus genus to the now known genus Paenibacillus (Genersch, 2010a; Genersch, 2008). The Bacillus genus included two species, Bacillus larvae and Bacillus pulvifaciens, which at the time were not yet associated with American foulbrood (Genersch, 2010a). With the classification of Paenibacillus, B. larvae and B. pulvifaciens were reclassified to two species of American foulbrood, P. larvae and 
Paenibacillus pulvifaciens respectively (Genersch, 2010a). However, the molecular similarity between $P$. larvae and $P$. pulvifaciens caused a reshuffling of the Paenibacillus genus from two species to two subspecies $P$. larvae larvae and $P$. larvae pulvifaciens (Genersch, 2010a). Most recently, through a lack of diverse pathologies between the $P$. $l$. larvae and $P$. l. pulvifaciens, the subspecies were discarded merging into one species $P$. larvae (Genersch, 2010a). The reclassification of the $P$. l. larvae and $P$. l. pulvifaciens without subspecies differentiation into P. larvae has allowed for a new direction in American foulbrood epidemiology studies, especially towards genetic analysis (Genersch et al., 2006; Genersch, 2010a).

American foulbrood's global distribution has led to the agreement that a reliable database on the genotypic identification of $P$. larvae is essential (Genersch, 2010a). With a look towards an internationally consistent methodology for the genetic analysis of $P$. larvae's subgroups and genotypes, the 'COLOSS beebook' was formulated. The 'COLOSS beebook' provides standardised methodologies for the genetic analysis of $P$. larvae, which are now commonly applied in international studies (de Graaf et al., 2013; Genersch, 2010a).

Repetitive sequence based polymerase chain reaction (rep-PCR) has been successfully used for the genetic identification of $P$. larvae field strains, using primers that amplify the 16S rRNA gene region (Alippi et al., 2004; Genersch, 2010a; Ryba et al., 2012). Other microbiology techniques for $P$. larvae genetic analysis exist such as pulsed-field gel electrophoresis and random amplified polymorphic DNA, though rep-PCR using marker ERIC, and primers BOX A1R, and MBO REP1 is considered the most accessible and standardised method for $P$. larvae genetic identification, allowing for comparison between studies (Genersch, 2010a; Genersch \& Otten, 2003, de Graaf et al., 2013). Using rep-PCR with marker ERIC, and primers BOX A1R, and MBO REP1 gives identification of the 
genotype and subgroups of $P$. larvae through the reading of banding patterns (Loncaric et al., 2009).

Of Paenibacillus larvae's four ERIC genotypes (ERIC I, II, III, and IV), ERIC I and II are consider the most significant as both are currently identified in honey bee field populations (Alippi et al, 2004; Poppinga et al., 2012). ERIC I has been recorded in both Europe and America, with ERIC II cited as restricted to Europe. ERIC III and IV only occur in laboratory collections (Genersch, 2010a; Poppinga et al., 2012).

Studies have shown that the different ERIC genotypes are related to the virulence of the disease (Genersch et al., 2005). ERIC II-IV exhibit a high larval level virulence, killing infected larvae within 5-7 days compared to ERIC I, which exhibits a lower larval level virulence with a longer 'killing time' (12-13 days) (Poppinga et al., 2012). Conversely, ERIC I is recorded to have higher colony level virulence than ERIC II-IV, due to its longer prevalence within the infected hive. ERIC I's longer prevalence is attributed to its longer killing time (Poppinga et al., 2012). The longer killing time delays the displaying of American foulbrood symptoms, causing the disease to be 'undiagnosed' by the nurse bees and the infected larvae to be capped for pupation rather than removed (Genersch, 2010a; Genersch, 2008; Poppinga et al., 2012). This allows ERIC I to have an extended presence in the hives, increasing the opportunity to for spread. ERIC II, due to its faster killing time, produces symptoms before capping and is recognised by the nurse bees, leading to the infected larvae being removed before spore proliferation, decreasing the opportunity for the disease's spread (Genersch, 2010a; Genersch, 2008; Poppinga et al., 2012). A colony infected with ERIC I is reported to exhibit a more rapid collapse compared to a colony infected with ERIC II (Genersch, 2008). 
Subgroups of $P$. larvae, identified through the use of BOX A1R and MBO REP1 primers, are either categorised within the ERIC I and ERIC II genotypes or remain uncategorised. The BOX A1R and MBO REP1 primers identify the subgroups ' $A, a$, and $\alpha$ ' and ' $B, b, \beta$, and $E$ ' respectively, with ERIC I and II being identified as ' $e$ ' and ' $E$ ' respectively (Loncaric et al., 2009; Peters et al., 2006; Genersch \& Otten, 2003). The subgroups $A b, a b, \alpha b$ are categorised into ERIC I, and $A B, a B, \alpha B$ categorised into ERIC II; subgroups $a \beta$ and $A B$ are yet to be categorised (Table 1.1).

Table 1.1: The categorisation of Paenibacillus larvae's genetic subgroups in ERIC genotypes, identified through the rep-PCR using the primers BOX A1R and MBO REP1. Subgroups are categorised into either ERIC I genotype (e), ERIC II genotype $(E)$, or Not categorised (yet to be classified into ERIC genotype) ${ }^{1}$ (Loncaric et al., 2009; Peters et al., 2006; Genersch \& Otten, 2003). Results are based on banding patterns expressed in gel electrophoresis.

\begin{tabular}{|c|c|c|}
\hline ERIC I $(e)$ & ERIC II $(E)$ & Not categorised \\
\hline$A b$ & $A B$ & $a \beta$ \\
$a b$ & $a B$ & $A B$ \\
$\alpha b$ & $\alpha B$ & \\
\hline
\end{tabular}

${ }^{1}$ Genetic subgroups, identified by primers BOX A1R and MBO REP1 in rep-PCR, ostensibly lack categorisation into genotypes ERIC III and IV.

\section{Objectives}

Objective 1: This thesis aims to identify the genetic subgroups of Paenibacillus larvae in New Zealand field strains using rep-PCR with the primer MBO REP1. I have chosen to use 
the primer MBO REP1 for the genetic identification of $P$. larvae, as subgroups identified by this primer can be differentiated into the ERIC I and ERIC II genotypes based on subgroup differentiation in previous papers (Genersch \& Otten, 2003; Loncaric et al., 2009; Peters et al., 2006). A genetic analysis of $P$. larvae will provide the first insight to the genetic subgroups and genotypes present in New Zealand. As the New Zealand honey bee lineage originates from the importation of European and American stock, there is potential for both ERIC I and ERIC II to be identified. ERIC I is hypothesised to be the most abundant strain in New Zealand, given it is the most prevalent strain globally (Genersch, 2010a; Poppinga et al., 2012).

Objective 2: This thesis will analyse temporal and geographic data on reported American foulbrood infections in New Zealand's registered hives and apiaries. The study period will be from 1994 to 2013, encompassing 20 years of infection reports in New Zealand overall and within seven regional boundaries of New Zealand. The monthly trends in American foulbrood reports for registered hives and apiaries will be examined. It is hypothesised that both regionally and nationally, American foulbrood infection rates in New Zealand's registered hives and apiaries would have decreased, based on previous analysis and the implementation of new management strategies and laws in 1998 (Matherson \& Reid, 2011).

The following chapter (Chapter Two) will be presented in the form of a manuscript in preparation for publication, therefore some repetition may occur between Chapter One and Chapter Two. 


\section{CHAPTER TWO}

\section{Introduction}

American foulbrood is a globally distributed, highly contagious honey bee brood disease (Genersch, 2008; Lindstrom et al., 2008b). It is a devastating and severe disease that leads to the collapse of infected colonies (Genersch, 2010b; Lindstrom et al., 2008a; D'Alessandro et al., 2007).

The causative agent Paenibacillus larvae is a Gram-positive, spore-forming bacterium, which through the ingestion of spores infects the honey bee brood (Alippi et al., 2004). Within American foulbrood literature, including the 'COLOSS beebook', the use of rep-PCR with ERIC marker, BOX A1R, and MBO REP1 primers has become a well-established method for the identification of $P$. larvae's genetic subgroups and genotypes, allowing for comparison between studies internationally (de Graaf et al., 2013; Genersch \& Otten, 2003; Loncaric et al., 2009; Peters et al., 2006).

The genotypes ERIC I, II, III, and IV have been identified in P. larvae (Alippi et al., 2004). ERIC I has been recorded in European and American continent isolates, with ERIC II cited as restricted to European isolates (Genersch, 2010a; Poppinga et al., 2012). ERIC III and IV have not been recorded in field populations in "recent years" (Genersch, 2010a) and now appear to be restricted to laboratory collections (Poppinga et al., 2012).

The ERIC genotypes are linked to the virulence of $P$. larvae in infected hives (Genersch \& Otten, 2003). ERIC II-IV exhibit a higher larval level virulence than ERIC I, killing the 
infected larvae within 5-7 days. Attributing to ERIC I's lower larval level virulence, due to the 'killing time' of 12-13 days, ERIC I exhibits a higher colony level virulence (Poppinga et al., 2012). The higher colony level virulence of ERIC I leads to a more rapid collapse of the infected colony than colonies infected with ERIC II-IV (Genersch, 2008; Poppinga et al., 2012).

The method of rep-PCR with primers BOX A1R and MBO REP1 is used to identify the $P$. larvae subgroups ' $A, a$, and $\alpha$ ' and ' $B, b, \beta$, and $E$ ' respectively. These subgroups are categorised within ERIC I, ERIC II, or are yet to be categorised (Table 1.1) (Loncaric et al., 2009; Peters et al., 2006; Genersch \& Otten, 2003).'Alpha' subgroups are seemingly ambiguous when categorised into the ERIC genotypes with ' $A$ ' and ' $a$ ' being differentiated into both ERIC I and II. Conversely, the 'beta' subgroups ' $b$ ' and ' $B$ ' can be differentiate into ERIC I and II respectively, with ' $\beta$ ' and ' $L$ ' yet to be categorised (Loncaric et al., 2009; Peters et al., 2006; Genersch \& Otten, 2003).

American foulbrood, introduced to New Zealand in 1877, is recorded throughout the country and is considered to be devastating to New Zealand's apiculture industry (PalmerJones, 1964; Goodwin, 2006). Since 1991, control of American foulbrood in New Zealand has been administrated under the American foulbrood National Pest Management Strategy (AFB NPMS). In 1998, AFB NPMS legislatively employed the aim of reducing American foulbrood hive infection rates to $0.1 \%$, or one in a thousand hives (Biosecurity Order, 1998). Previous analysis reported a decreas in New Zealand's American foulbrood infection rate from 1990 to 1998 . With hive's infection rates fluctuating between $0.31 \%$ and $0.26 \%$ from 1999 to 2006 (Goodwin, 2006). The burning of infected hives and sterilisation of infected equipment is the only legal method of control for American foulbrood in New Zealand, with the use of chemical controls banned (Goodwin, 2006). 
I conducted an epidemiological study on American foulbrood and its causative agent Paenibacillus larvae in New Zealand's registered hives and apiaries Firstly, focus was given to genetically analysing and identifying $P$. larvae subgroups using the rep-PCR with MBO REP1 primers. The bacterial isolates analysed were from honey bee samples gathered over the period of 2011-2014 from the North and South Island. The MBO REP1 primers were used to identify $P$. larvae's 'beta' genetic subgroups. By identifying the 'beta' subgroups, ERIC genotypes and frequency can also be concluded (Genersch \& Otten, 2003; Loncaric et al., 2009; Peters et al., 2006). Secondly, a statistical analysis was conducted to examine temporal and geographical trends in American foulbrood infection rates in New Zealand's registered hives and apiaries from 1994 to 2013.

\section{Methods and Materials}

\section{Genetic analysis of Paenibacillus larvae}

\section{Sample collection}

New Zealand hives that present the clinical symptoms of American foulbrood had samples taken by the beekeepers and were sent to Plant and Food Research Ltd (Hamilton, New Zealand) for laboratory diagnosis. The samples were taken directly as adult worker bees or broodcomb. Once collected, the samples were placed in either a snap-lock airtight plastic bag or a lid covered plastic jar and sent by mail. Adult bee and broodcomb samples are placed in a $-30^{\circ} \mathrm{C}$ freezer for long-term storage viability. Subsamples were removed from the original samples when required for diagnostic testing of Paenibacillus larvae, thus American foulbrood.

Plant and Food Ltd provided the samples used in this thesis. A total of 172 samples that had been previously found to be infected with $P$. larvae were cultivated on agar. Of the 172 
samples, 42 presented colony growth and were identified as $P$. larvae colonies. These colonies were from adult honey bee workers samples and broodcomb (larvae) samples. These samples had previously been collected during 2011 to 2014 from six New Zealand regions: Whangarei, Hamilton, Tauranga, Palmerston North, Blenheim, and Canterbury (Table 2.1, Figure 2.1). American foulbrood has been reported in the Otago region, however, no samples were available for genetic testing.

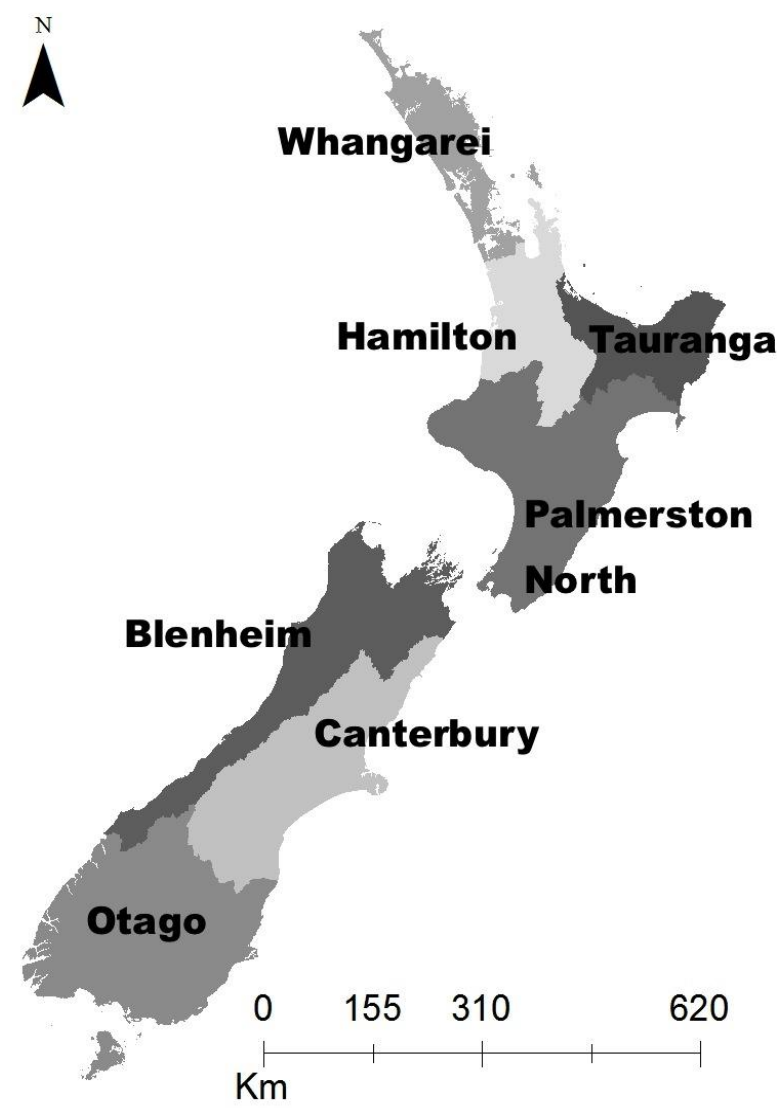

Figure 2.1: The seven regions of New Zealand. These regions are used as the regional boundaries in this thesis's genetic and statistical analysis. 
Table 2.1: The governmental geographic boundaries (region locales) encompassed within the seven regions of New Zealand. Registered hive and apiary locations are assigned into regions based on their location.

\begin{tabular}{cl}
\hline Region & \multicolumn{1}{c}{ Region locales } \\
\hline Whangarei & Northland, Auckland \\
Hamilton & Waikato, King Country, Taupo, Coromandel \\
Tauranga & Bay of Plenty, Rotorua, Poverty Bay \\
Palmerston North & $\begin{array}{l}\text { Manawatu, Taranaki, Hawkes Bay, Wairarapa, } \\
\text { Wellington }\end{array}$ \\
Blenheim & Marlborough, Nelson, West Coast \\
Canterbury & Canterbury, Kaikoura \\
Otago & Otago, Southland \\
\hline
\end{tabular}

\section{Sample preparation}

The preparation for the cultivating of $P$. larvae from adult bee samples was based on Lindstrom and Fries' (2005) protocol. To cultivate a P. larvae sample, 30 adult female worker bees from a single hive were added to $10 \mathrm{ml}$ of sterilised deionised water and crushed into a solution. The solution was then heat treated with a waterbath at $70^{\circ} \mathrm{C}$ for 20 minutes to reduce contamination with 64 microlitres of the solution then spread onto Oxoid (CM1136) Brain Heart infusion agar (Forsgren et al., 2008; de Graaf et al., 2006). To cultivate a $P$. larvae sample from larvae, $1 \mathrm{~g}$ of larvae tissue, from a single hive, was spread directly onto the agar with a sterile glass hook using a streak technique (Alippi \& Reynaldi, 2006; Peters et al., 2006). As per the method of de Graaf et al. (2013) and Pinto et al., 2011 for agar preparation, Oxoid (CM1136) Brain Heart infusion agar (containing $1 \mathrm{mg}$ of thiamine hydrochloride per litre of agar to limit contamination) was used. Once samples were spread 
on the agar, the plates were inverted and incubated at $37.5^{\circ} \mathrm{C}$ with $5 \%$ carbon dioxide for 3 days (de Graaf et al., 2013; Bakonyi et al., 2003).

\section{Sample identification and storage}

Cultures produced from the incubation period that morphologically resembled P. larvae (grey-white in colour with a ropy texture when touched; Figure 2.2) underwent further identification (Genersch \& Otten, 2003).

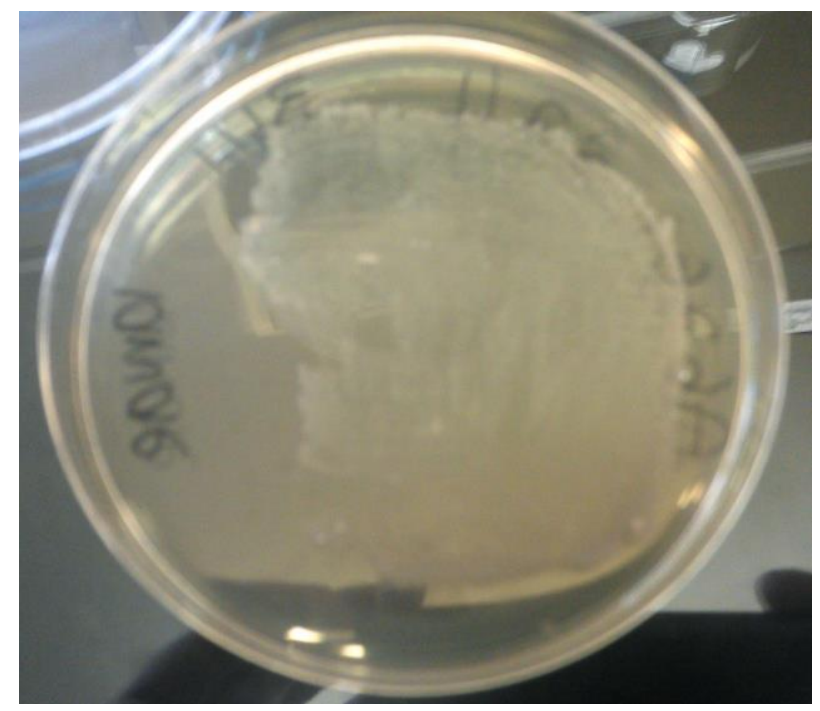

Figure 2.2: Three-day-old Paenibacillus larvae colony growth on Oxoid Brain Heart infusion agar. The 'ropy' texture of the colony with grey-white colouring gives a preliminary identification of $P$. larvae (Genersch \& Otten, 2003). The bacteria colony then undergoes an additional catalyst tests and gram staining for further positive identification of American foulbrood.

Two tests were preformed in order to confirm the identity of the cultures as P. larvae, based on Genersch and Otten's (2003) protocol. The first test was a catalyst test where a bactiloop swab removed part of the culture in question, which was then placed onto a microscopic slide. A drop of hydrogen peroxide was added to the slide, and the presence of 
$P$. larvae is indicated by the lack of bubbles produced from a lack of catalysis. The second test was gram staining in which a bactiloop swab was taken from the culture and placed onto a microscopic slide. The slide was then stained with crystal violet for 1 minute and washed off with water, then with iodine for 1 minute and washed off with water, then with ethanol (70\%) for 30 seconds that was dabbed off, and finally stained with safranin O solution for 10 seconds then washed off with water (Bakonyi et al., 2003). The slides were examined under a microscope using oil immersion and 100x magnification. A positive result for P. larvae is given by the observation of purple stained vegetative rods and spores under magnification (Yoshiyama \& Kimura, 2009; Genersch \& Otten, 2003).

Once identified as $P$. larvae, the culture was entirely removed from the agar with a bactiloop, sealed into a $1 \mathrm{ml}$ cryovial with $0.5 \mathrm{ml}$ of glycerol and mixed well. The bacteria/glycerol suspension was labelled and placed into an $-80^{\circ} \mathrm{C}$ freezer for storage and later was used for genetic identification using the molecular methods described below (de Graaf et al., 2013; Alippi \& Reynaldi, 2006).

\section{DNA extraction}

In preparation for DNA extraction, cryovials were removed from the $-80^{\circ} \mathrm{C}$ freezer and the suspensions were transferred into microcentrifuge tubes. The microcentrifuge tubes were centrifuged for 10 minutes at $22^{\circ} \mathrm{C}$ at $13,200 \mathrm{rpm}$ causing the glycerol to separate from the bacteria pellet. The glycerol was then removed and discarded leaving the bacteria pellet in the microcentrifuge tube ready for extraction.

The bacteria extraction followed Instagene Matrix (Bio-Rad) listed instructions (Genersch \& Otten, 2003). The bacterial pellet was first resuspended in $1 \mathrm{ml}$ of autoclaved water and centrifuged for 1 minute at $11,000 \mathrm{rpm}$ with the supernatant then removed. The bacteria pellet was resuspended in $200 \mu 1$ of $6 \%$ Instagene Matrix (Bio-Rad), incubated in a heating 
block set at $56^{\circ} \mathrm{C}$ for 25 minutes, vortexed at high speed for 10 seconds, incubated for an additional 8 minutes at $100^{\circ} \mathrm{C}$, and again vortexed at high speed for 10 seconds. The solution was then centrifuged for 2 minutes 30 seconds at 11,000rpm. For each PCR reaction $1 \mu 1$ of the resulting supernatant of the bacteria solution was used.

\section{rep-PCR}

The standard method of de Graaf et al (2013), based on Loncaric et al.'s (2009) and Genersch \& Otten's (2003) protocol, was used to identify $P$. larvae's genetic subgroups ' $B$, $b, \beta$, and $E^{\prime}$ through rep-PCR DNA fingerprinting. The subgroups are obtained through DNA amplification by the primer MBO REP1 DNA sequence 5'CCGCCGTTGCCGCCGTTGCCGCCG-3'. The MBO REP1 primer produces distinct banding patterns ranging from $750 \mathrm{bp}$ to $1100 \mathrm{bp}$ on agarose gels (Table 2.1, Figure 2.2) (Genersch \& Otten, 2003; Peters et al., 2006). I chose to use the MBO REP1 primer as the genetic subgroups identified by this primer can be used to distinguish the genotypes ERIC I and ERIC II. Literature has segregated subgroups $b$ and $B$ into ERIC I and II respectively, whilst subgroups $\beta$ and $E$ are currently without ERIC categorisation (Table 1.1) (Genersch \& Otten, 2003; Loncaric et al., 2009).

Amplification reactions of $15 \mu \mathrm{l}$ of total volume included $1.5 \mu \mathrm{l} 10 \mathrm{x}$ buffer, $0.6 \mu 1$ of dNTPs $(5 \mathrm{mM}), 0.6 \mu 1$ of BSA $(10 \mathrm{mg} / \mathrm{mL}), 0.6 \mu 1$ of MBO REP1 $(10 \mu \mathrm{m}), 0.9 \mu 1$ of $\mathrm{MgCl}_{2}$, 9.74 $\mu \mathrm{l}$ of $\mathrm{ddH}_{2} \mathrm{O}, 0.06 \mu \mathrm{l}$ Taq DNA polymerase $(5 \mathrm{U} / \mu \mathrm{l})$, and $1 \mu \mathrm{l}$ of extracted bacteria solution. PCR cycle parameters used for the MBO REP1 primers were from Loncaric et al. (2009), which follows $95^{\circ} \mathrm{C}$ for 5 minutes; 35 cycles of $94^{\circ} \mathrm{C}$ for 1 minute, $59^{\circ} \mathrm{C}$ for 1 minute, and $72^{\circ} \mathrm{C}$ for 1.5 minutes; and a final $72^{\circ} \mathrm{C}$ for 10 minutes.

Five microlitres of loading dye and two microlitres of PCR product were mixed together and loaded on a $1.5 \%$ agarose gel. Electrophoresis was carried out in $0.5 \mathrm{TBE}$ buffer, at 
400mA, 90V, for 30 minutes with HyperLadder 1 (BioLine) for reference. The DNA bands were stained in ethidium bromide $\left(1 \mu \mathrm{g} \mathrm{ml}^{-1}\right)$ for 15 minutes, visualised by UV light and photography (Figure 2.3).

Table 2.2: The individual banding patterns for Paenibacillus larvae's four genetic subgroups $B, b, \beta$, and $E$, identified by using the rep-PCR with primers MBO REP1. The bands are distinguished by gel electrophoresis and are ethidium bromide stained. Subgroups $b$ and $B$ are segregated into ERIC I and ERIC II respectively. Subgroups $\beta$ and 5 are seemingly without ERIC categorisation.

\begin{tabular}{c|c}
\hline $\begin{array}{c}\text { MBO REP1 } \\
\text { subgroups }\end{array}$ & \multicolumn{1}{c}{ Banding pattern } \\
\hline$B$ & Band present at 1100bp, band absent at 1030bp \\
$b$ & Band present at 1030bp, band absent at 1100bp \\
$\beta$ & Lack of bands at 1030bp and 1100bp \\
$B$ & Bands present at 1030bp and 1100bp, simultaneously \\
\hline
\end{tabular}

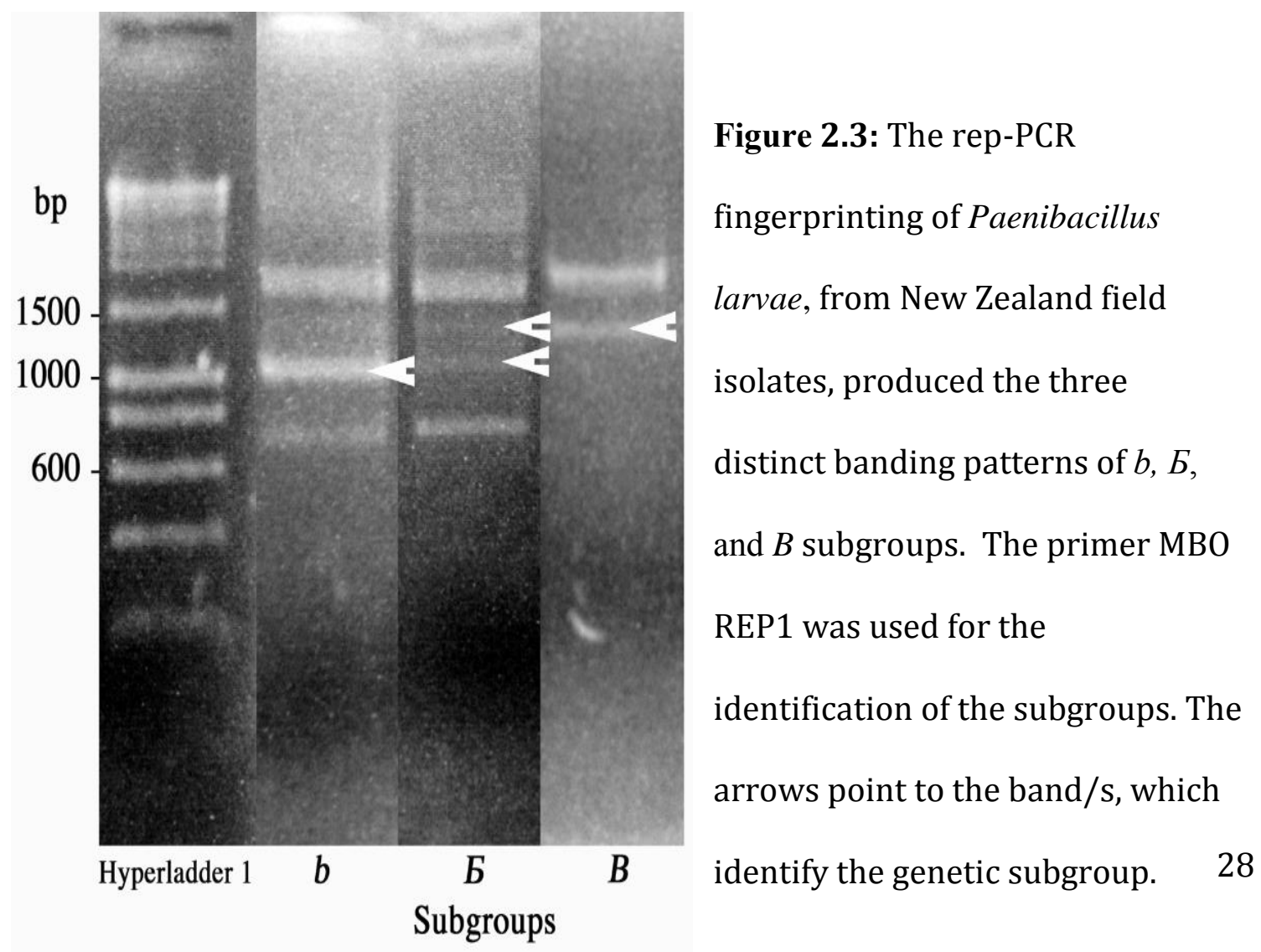




\section{Statistical analysis of American foulbrood historic data}

\section{Data source}

Beekeepers in New Zealand under law must register themselves, their hives, and their apiaries and its location. Under the Disease Elimination Conformity Agreement (DECA), a formal agreement between beekeeper and AFB NPMS, hives must legally be inspected annually for American foulbrood by a certified beekeeper (Goodwin, 2006). It is recommended to examine hives for American foulbrood during particular months and before the removal of hive products or equipment (Matherson \& Reid, 2011). If hives are infected, under New Zealand law the infected hive must be reported within seven days of the disease being discovered and destroyed through burning. Infections are reported by the beekeeper or by Plant and Food Research Ltd, if samples sent to Plant and Food Research Ltd tested positive for American foulbrood.

The New Zealand beekeeping reporting 'year' runs from July 1st to June 30th. The year the initial July falls into is the year presented in data output. For example, the beekeeping year of July 1st 2013 to June 30th 2014 is represented as 2013 in data outputs.

Data used for this thesis' statistical analysis was accessed from AsureQuality Ltd and Plant and Food Research Ltd, government owned institutions, and the New Zealand Beekeeper Journal. Data analysed was New Zealand's registered beekeepers, hives, and apiaries numbers, New Zealand American foulbrood infection reports, and the location of the infected hives and apiaries.

The dates analysed were chosen as statistical reporting had become consistent and reliable from that start date onwards. For beekeepers registration, numbers were from 1984 to 2013, and for registered hives and apiaries from 1964 to 2013. The data on American foulbrood 
infection reports in New Zealand was presented as separate individual reports per year from 1994 to 2013. For the American foulbrood analysis each year was assessed independently as the same apiary may be infected with the disease in different years. The data analysis on the monthly trends of American foulbrood reports examined data from 1997 to 2013. The '1997' date was chosen as the start date, as from 1997 onwards, the month in which an American foulbrood report is made is noted in the system. Prior to 1997, all American foulbrood reports were entered into the system in December, therefore not providing distinctive months when the report was made. The reports were averaged for each month from 1997 to 2013.

Limitations may be experienced with this data. The data does not account for unregistered beekeepers, hives, or apiaries. Nor does it account for undiagnosed American foulbrood infections or infections that were not reported. All infection rates of American foulbrood in this thesis are based on American foulbrood reports, therefore the use of words 'reports' and 'infection rates' towards hives and apiaries will be used interchangeably. Data on regional registered hives and apiaries was not obtainable in 1999, as the New Zealand Beekeeper Journal did not provide an American foulbrood infection report for that year. Therefore, the regional hive and apiary infection rates in 1999 have been excluded from the analysis.

The seven regions used in this thesis are based on boundaries applied in previous American foulbrood analysis. The seven regions are: Whangarei, Hamilton, Tauranga, Palmerston North, Blenheim, Canterbury, and Otago (Figure 2.1). These regions represent the locations of registered apiaries and encompass multiple governmental geographic boundaries (Table 2.1).

The Coromandel is recognised as an area within the Waikato for the data gathered on American foulbrood infection rates in New Zealand hives and apiaries. However, for the data gathered on the overall number of hives and apiaries registered per region, the Coromandel is 
recognised a part of Tauranga. There is a consistent error for all years in data output, as the Coromandel's American foulbrood infections will be associated with Waikato's overall hive and apiary numbers rather than Tauranga's.

\section{Data analysis}

The statistical analysis within this thesis was performed using the dedicated statistical software R 3.0.3. Data mapping was achieved through ArcGIS 10.2. Statistical tests were 2tailed, used standard errors, with P-values considered significant if $\leq 0.05$.

Generalised linear models (GLM) were applied to examine the change in a region's registered hive or apiary infection rate (dependent variable) over the independent variable of time (a year). The average New Zealand infection rate for hives or apiaries was used as the reference level. Registered hives and apiaries' infection rates were analysed separately. Data in hive and apiary infection rates were gathered from 1994 to 2013. A binominal distribution model was used. The GLM equations accounted for the total number of registered hives or apiaries in each region. Registered hives and apiaries' infection rates were both analysed to provide an overall view of American foulbrood infection rates.

To find whether American foulbrood infection rates in New Zealand hives and apiaries (dependent variable) on a national level were increasing or decreasing annually (independent variable), generalised linear models were used. Data in hive and apiary infection rates were gathered from 1994 to 2013 . The GLM equations accounted for the total number of registered hives or apiaries in each region. A binominal distribution model was used. Regional infection rates from 1994 to 2013 were used in the GLM equation. Registered hives and apiaries' infection rates were analysed separately. 


\section{Results}

\section{Genetic analysis of Paenibacillus larvae}

Of the 172 samples that were cultivated on agar, 42 produced $P$. larvae colonies. Of those 42 isolates, 33 produced results post the rep-PCR. Multiple attempts were made in culturing additional samples and the running of rep-PCR analysis on isolates that had previously failed to produce results. Table 2.3 shows the $33 P$. larvae field isolates from the six regions of New Zealand (gathered from 2011 to 2014) that produced fingerprinting results from the repPCR with the primers MBO REP1.

The 33 isolates are predominantly divided into the years $2011(\mathrm{n}=10), 2012(\mathrm{n}=9)$, and $2013(n=12)$ (Table 2.3). These years represent the year in which the samples from a suspected American foulbrood hive were sent to Plant and Food Ltd for diagnosis. The isolates diagnosed during 2014 had the lowest sample size $(n=2)$, because at the time of analysis only a partial year's samples were available.

Table 2.3: The regions from which the 33 Paenibacillus larvae isolates originated. Isolates are from samples taken from infected hives within six regions of New Zealand from 2011 to 2014. The 33 isolates generated results when processed through rep-PCR using the MBO REP1 primers. No samples were available from Otago for genetic analysis.

\begin{tabular}{lccccc}
\hline Regions & 2011 & 2012 & 2013 & 2014 & Total \\
\hline Whangarei & 2 & 3 & 7 & 0 & 12 \\
Hamilton & 1 & 0 & 1 & 0 & 2 \\
Tauranga & 0 & 0 & 2 & 0 & 2 \\
Palmerston North & 4 & 3 & 1 & 0 & 8 \\
Blenheim & 1 & 0 & 0 & 1 & 2 \\
Canterbury & 2 & 3 & 1 & 1 & 7 \\
\hline Total & 10 & 9 & 12 & 2 & 33 \\
Total \% & 30 & 27 & 36 & 6 & \\
\hline
\end{tabular}


The rep-PCR using primers MBO REP1 produced three genotypic subgroups of Paenibacillus larvae from the New Zealand field strains tested. The three genotypic subgroups detected were $B, b$, and $Б$. Subgroups $B$ and $b$ are bifurcated into genotypes ERIC II and ERIC I respectively (Genersch \& Otten, 2003). Based on the results of the isolates, ERIC II was the most common genotype. Subgroup $B$ was the most prominent and frequently detected subgroup in the isolates, occurring in all six regions and in 15 (46\%) of the 33 isolates (Table 2.4). Subgroup 5 was the second most commonly detected subgroup, both

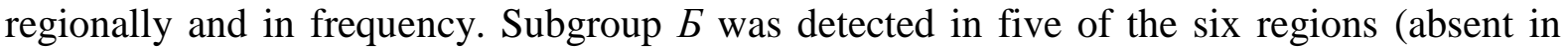
Blenheim) and occurred in $10(30 \%)$ of 33 isolates (Table 2.4). Subgroup $b$ was occurred in 8 (24\%) of the 33 isolates and was detected in four of the six regions (absent in Hamilton and Tauranga) (Table 2.4). Figure 2.4 shows a visual summary of the regional variance in the frequency and presence of genetic subgroups $B, b$, and $\overline{\text {. }}$.

Table 2.4: The occurrence of Paenibacillus larvae subgroups $B, b$, and $E$ in six regions of New Zealand based on genetic fingerprinting results of isolates.

\begin{tabular}{lcccc}
\hline Regions & \multicolumn{3}{c}{ Subgroups } \\
& $B$ & $b$ & $b$ & Total \\
\hline Whangarei & 3 & 5 & 4 & 12 \\
Hamilton & 1 & 0 & 1 & 2 \\
Tauranga & 1 & 0 & 1 & 2 \\
Palmerston North & 4 & 1 & 3 & 8 \\
Blenheim & 1 & 1 & 0 & 2 \\
Canterbury & 5 & 1 & 1 & 7 \\
\hline Total & 15 & 8 & 10 & 33 \\
Total \% & 46 & 24 & 30 & \\
\hline
\end{tabular}




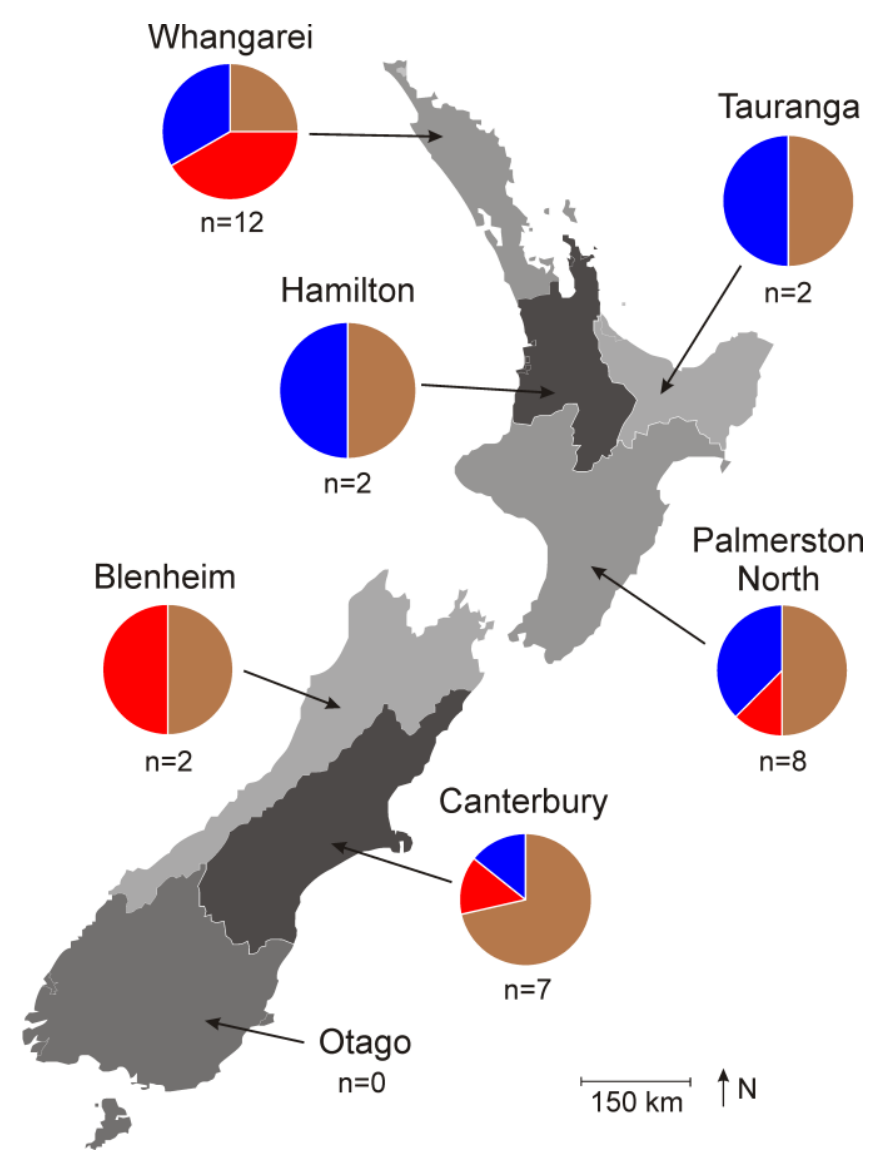

Figure 2.4: The regional variance in the frequency and occurrences of Paenibacillus larvae

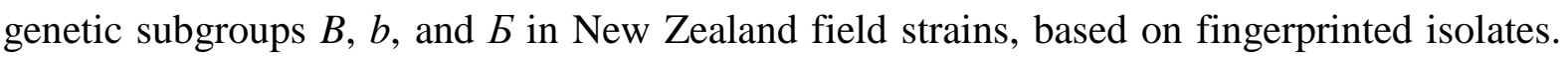
Subgroups represented by colours: $B$, brown; $b$, red; $E$, blue.

Of the 33 isolates, 24 were from North Island hives. Within the North Island, the subgroups $B$ and $E$ were detected in $37.5 \%$ of the 24 isolates. Subgroup $b$ was detected in $25 \%$ of the 24 isolates. As subgroup $B$ is yet to be categorised into an ERIC genotype, ERIC II was the most common genotype recorded for the North Island based on isolates.

Nine of the 33 isolates were from South Island hives. Subgroup $B$ was detected most frequently in the South Island isolates (67\%), with subgroup $b$ and $E$ detected in $22 \%$ and $11 \%$ respectively. Based on these results ERIC II was the most frequent genotype for the South Island, in addition to being the most frequently detected genotype in the North Island and New Zealand overall. 
Though figure 2.4 suggests that all three subgroups are distributed throughout New Zealand more sampling would further confirm this distribution. Additionally, more samples would be required before confirming the prevalence of $P$. larvae genotypes in New Zealand field strains, especially for the South Island regions, which had only nine available samples for analysis, with no samples available for analysis in the Otago region.

\section{Statistical analysis of American foulbrood historic data}

\section{Registered hives, apiaries, and beekeepers trends}

To gain an overall view of beekeeping in New Zealand, the trends in the number of registered beekeepers (from 1984 to 2013) and registered hives and apiaries (1964 to 2013) in New Zealand were analysed (Figure 2.5).

Plots of New Zealand's registered hives and apiaries numbers showed a near exponential increase since 2004 for hives and 2006 for apiaries. This recent growth in hive and apiary numbers surpasses the pervious peak in reported 1986. Understandably, hive numbers are increasing at a higher rate than apiaries. This result is likely as an apiary may contain multiple hives, meaning hives will always equal to or higher than the number of apiaries (Matherson \& Reid, 2011).

Plots of New Zealand registered beekeeper numbers from 1984 to 2013 follows a similar trend to hive and apiary registration during that period, with New Zealand beekeepers currently experiencing an increase in numbers from 2008 onwards (Figure 2.5). However, dissimilar to registered hive and apiary numbers, beekeeper numbers have not surpassed the previous peak in 1986. 

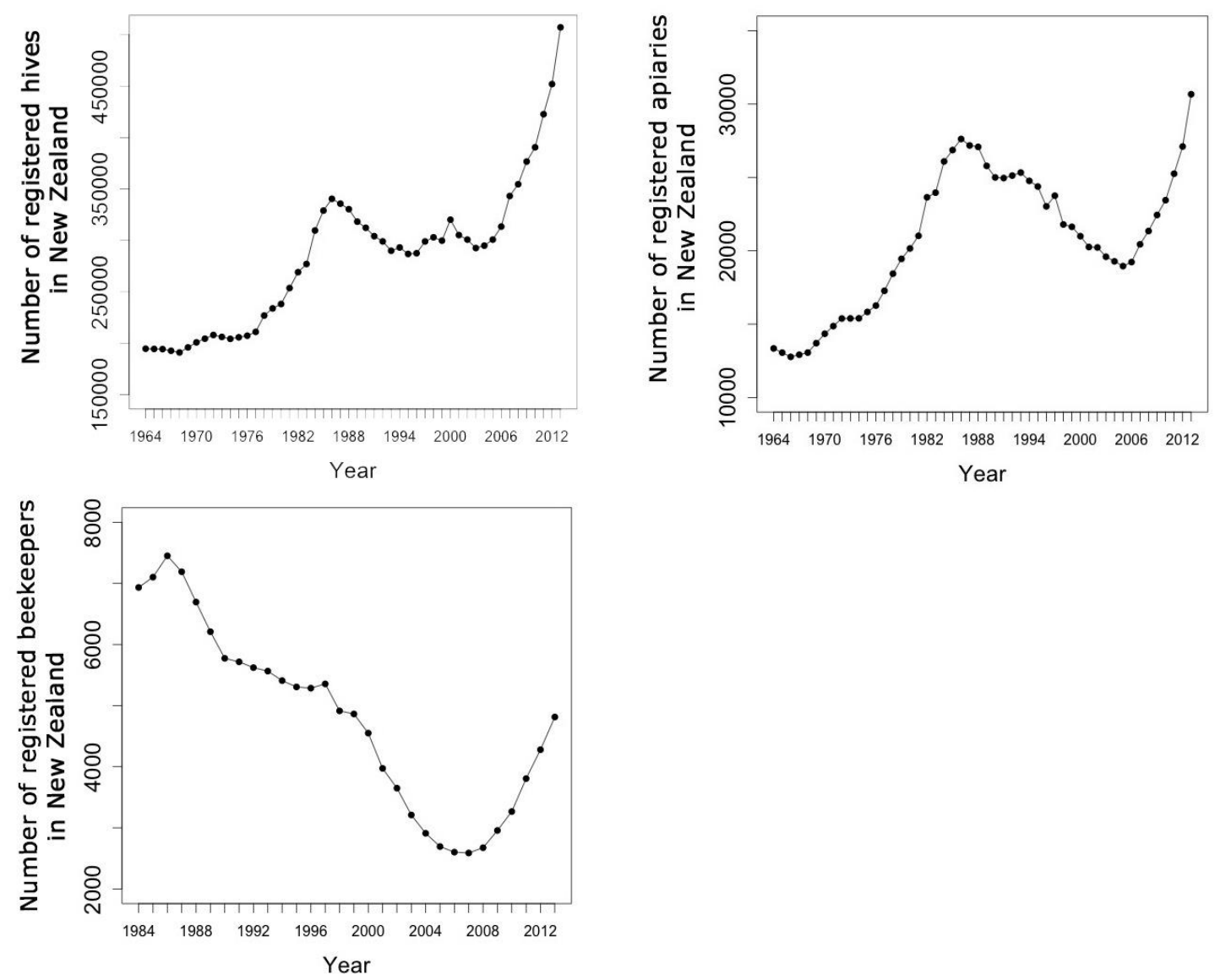

Figure 2.5: The trends in New Zealand's registered hive, apiary, and beekeeper numbers. Hives and apiaries are documented from 1964 to 2013, with beekeepers are documented from 1984 to 2013.

\section{American foulbrood infections in New Zealand registered hives and apiaries}

The generalised linear model (GLM) results showed that overall New Zealand's registered hives and apiaries' American foulbrood infection rates are significantly decreasing annually from the year 1994 to 2013 (GLM hives: $b=-0.043, z=41.51, p<0.001$ ) (GLM apiaries: $b=-0.016, z=-11.97, p<0.001)$.

Figure 2.6 and 2.7 shows the temporal and geographical shifting of American foulbrood infection rates in regional hives and apiaries in five-year periods from 1994 to 2013. The infection rate for the maps and box plots represent the percentage of registered hives or 
apiaries infected with American foulbrood. The box plots gives a detailed picture of New Zealand's average infection rates, based on the seven regions infection rates, as well as the seven regions infection rates during four five-year periods from 1994 to 2013. The maps display the average infection rate for each of the seven regions during the same period as the box plots.

The box plot 'New Zealand' in figure 2.6 represents the average American foulbrood infection rate for New Zealand hives in the four five-year periods from 1994 to 2013. The box plots shows a slight increase in hive infection rates during 1999-2003, followed by a decline for the periods 2004-2008 and 2009-2013. American foulbrood infection rates in New Zealand hives shows greater variation then infection rates in New Zealand apiaries during 1994-1998. However, after the 1994-1999 period, variations in the infection rates decreased for both hives and apiaries, suggesting a decrease in the annual fluctuation in the diseases' spread.

The box plot 'New Zealand' in figure 2.7 represents the average American foulbrood infection rate in New Zealand apiaries in the four five-year periods from 1994 to 2013. These results show a similar trend to that seen with the New Zealand hives infection rates (Figure 2.6) with a peak in apiary infection rates during the 1999-2003 period, then a continued decline in infection rates from 2004 onwards. 

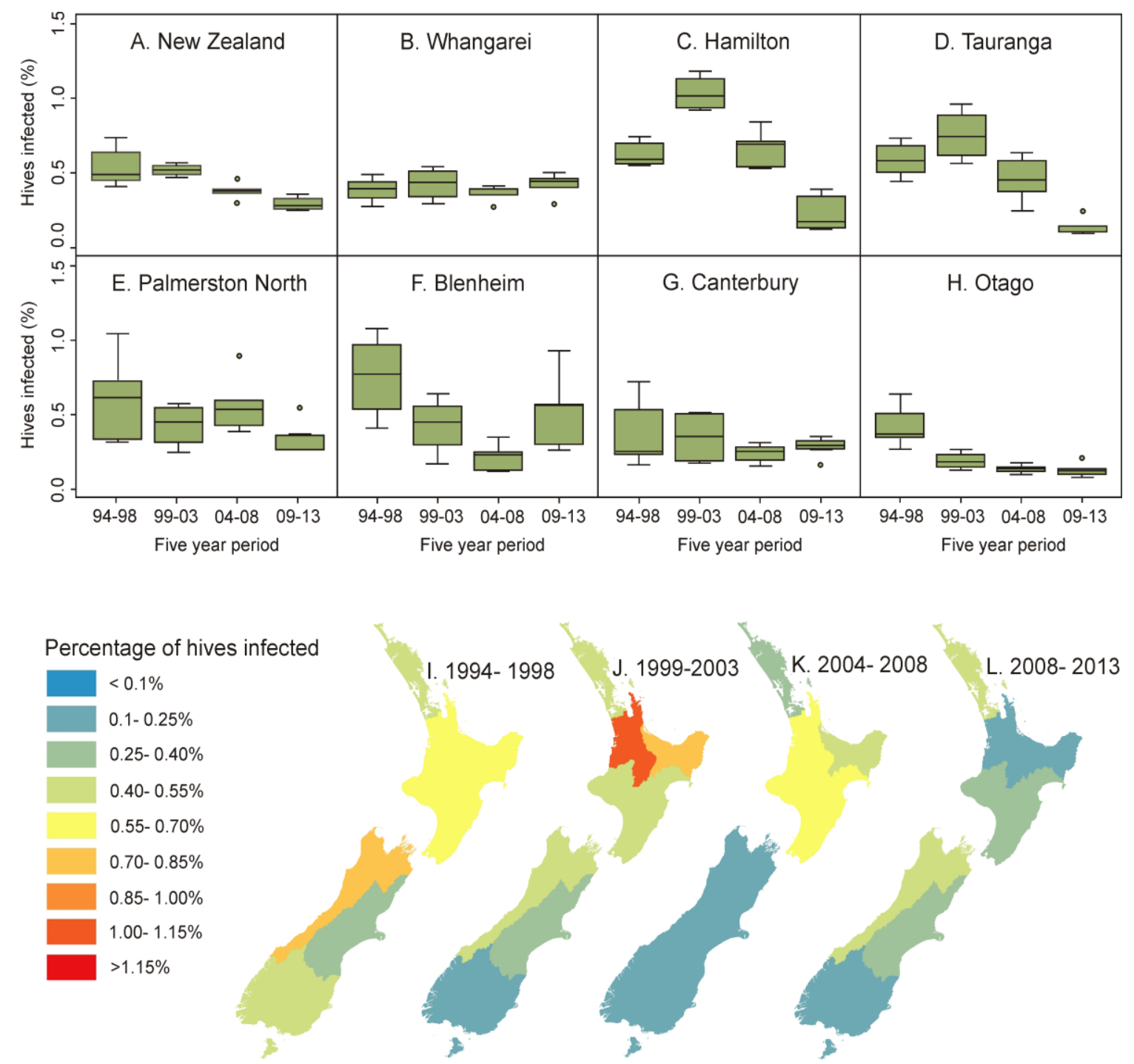

Figure 2.6: The maps show four five-year periods of the average percentage of New Zealand registered hives infected with American foulbrood regionally, based on infection reports. The five-year periods are from 1994 to 2013 and are divided as I) 1994-1998; J) 1999-2003; K) 2004-2008; L) 2009-2013. Regions represented on the map are labelled within the box plots $(\mathrm{B}-\mathrm{H})$. The box plots present the percentage of New Zealand registered hives infected with American foulbrood during each of the 

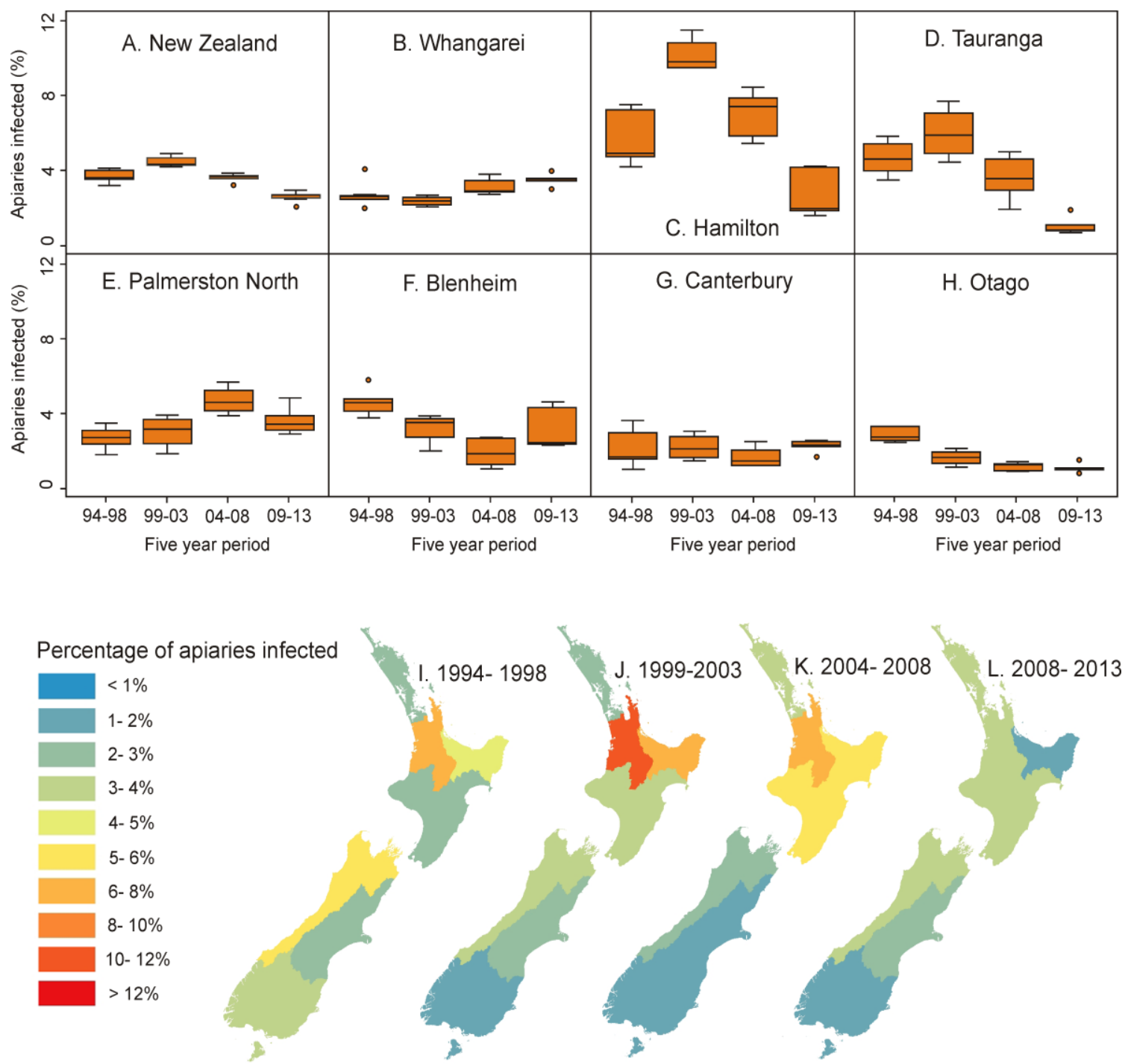

Figure 2.7: The maps show four five-year periods of the average percentage of New Zealand registered apiaries infected with American foulbrood regionally, based on infection reports. The five-year periods are from 1994 to 2013 and are divided as I) 1994-1998; J) 1999-2003; K) 2004-2008; L) 2009-2013. Regions represented on the map are labelled within the box plots $(\mathrm{B}-\mathrm{H})$. The box plots present the percentage of New Zealand registered apiaries infected with American foulbrood during each of the five-year periods. 


\section{American foulbrood infections in regional registered hives}

Generalised linear models were used to analyse the annual change in the infection rate of American foulbrood in a region's registered hives from 1994 to 2013, when compared to the New Zealand average. Both registered hive and apiary were analysed and done so separately to give a better understanding of regional infection rate of American foulbrood.

The American foulbrood infection rate in Whangarei's registered hives increased annually over the study period (GLM: $b=0.044, z=10.87, p<0.001$ ). Figure 2.6 showed a fluctuation in the average percentage of registered hives infected with American foulbrood between $0.25-0.4 \%$ to $0.4-0.55 \%$ during 1994 to 2013 . For the $2009-2013$ period, Whangarei was reported to have the highest regional infection rate for New Zealand.

The American foulbrood infection rate in Hamilton's registered hives decreased annually over the study period (GLM: $b=-0.011, z=-3.24, p<0.005$ ). During 1999-2003 Hamilton was observed as having the highest percentage of hives infected $(1-1.15 \%)$ for the entirety of the study for all regions (Figure 2.6). From 2004, trends showed a sustained substantial decrease in the percentage of Hamilton's hives infected with American foulbrood.

The American foulbrood infection rate in Tauranga's registered hives decreased annually over the study period (GLM: $b=-0.036, z=-9.81, p<0.001$ ). Similar to Hamilton's trends, Tauranga exhibited a peak in infection rates during the $1999-2003$ period with $0.85-1 \%$ of the region's registered hives infected with American foulbrood (Figure 2.6). Conversely, during 2009-2013 both Hamilton and Tauranga were observed to have the lowest hive infection rate trends (alongside Otago) with $0.1-0.25 \%$ of registered hives being infected with American foulbrood. 
The American foulbrood infection rate in Palmerston North's registered hives increased annually over the study period (GLM: $b=0.008, z=2.29, p<0.051$ ). Palmerston North's infection rate showed a fluctuating trend from 1994 to 2013 , with $0.25-0.4 \%$ to $0.55-0.7 \%$ of registered hives being infected with American foulbrood (Figure 2.6). Palmerston North's lowest American foulbrood infection rate trend was reported during the 2009-2013 period. Palmerston North box plots showed a high level of variation in infection rates. The substantial variation in Palmerston North's infection rates proposes a fluctuation in the number of hives infected per year. The variation showed less variance during the later period of the study (2009-2013), suggesting an increase in the consistency of the number of hives infected from year to year.

Blenheim was the sole region to have insignificant generalised linear model results (GLM: $b=0.001, z=0.23, p>0.051)$.

The American foulbrood infection rate in Canterbury's registered hives increased annually over the study period (GLM: $b=0.016, z=4.07, p<0.001)$. Canterbury's registered hives infection trends was shown to be fluctuating between the four five-year study periods (Figure 2.6). Similar to Palmerston North, Canterbury trends showed a high level of variation in the percentage of hives infected during the earlier part of the study (1994 to 2003) compared to the later part (2004 to 2013).

The American foulbrood infection rate in Otago's registered hives decreased annually over the study period (GLM: $b=-0.056, z=-11.36, p<0.001$ ). Otago was, based on trends, the sole region to have a sustained decline in American foulbrood infection rates from 1994 to 2013 (Figure 2.6). It was also the sole region in New Zealand, in respect to the average percentage of registered hives infected with American foulbrood, to maintain an infection rate of $0.1-0.25 \%$ from 1999 to 2013. 


\section{American foulbrood infections in regional registered apiaries}

Generalised linear models were used to analyse the annual change in the infection rate of American foulbrood in a region's registered apiaries from 1994 to 2013 when compared to the New Zealand average.

The American foulbrood infection rate in Whangarei's registered apiaries increased annually over the study period (GLM: $b=0.038, z=7.01, p<0.001$ ). A slight decreasing trend was recorded in the percentage of registered apiaries infected with American foulbrood during the 1999-2003 period (Figure 2.7). However, from 2004 onwards infection rates in Whangarei apiaries, based on percentages, were shown to be increasing.

The American foulbrood infection rate in Hamilton's registered apiaries decreased annually over the study period (GLM: $b=-0.019, z=-3.99, p<0.005)$. Figure 2.7 showed Hamilton's trends to have a steep decline in percentage of apiaries infected from 2004 to 2013. Hamilton shows a high level of variation in the percentage of apiaries infected for each five-year period, indicating that though the average infection rate displayed a decline, there is still a high level of fluctuation in the number of apiaries infected with American foulbrood. As this was maintained for the entity of the study, it may demostrate a natural dynamics of the disease.

The American foulbrood infection rate in Tauranga's registered apiaries decreased annually over the study period (GLM: $b=-0.025, z=-4.97, p<0.001$ ). Tauranga's trends showed a similar pattern to Hamilton's, with a peak in the average percentage of apiaries infected with American foulbrood in 1999-2003 (6-8\%) then a steep continued decline from 2004 to 2013 (Figure 2.7). During the 2009-2013 period, Tauranga's infection rate trend suggested the region was exhibiting one of the lowest percentages of infected apiaries. 
The American foulbrood infection rate in Palmerston North's registered apiaries increased annually over the study period (GLM: $b=0.033, z=6.86, p<0.001$ ). From 1994 to 2003, Palmerston North showed an increasing trend in the percentage of apiaries infected with American foulbrood (Figure 2.7). A slight decreasing trend was reported during 2009-2013 with the average percentage of infected apiaries dropping from 5-6\% in 2004-2008 to 4-5\% in 2009-2013.

The American foulbrood infection rate in Blenheim's registered apiaries decreased annually over the study period (GLM: $b=-0.017, z=-2.85, p<0.005)$. Figure 2.7 showed an increasing level of variation between study periods, indicating a possible trend towards greater fluctuation in the number of apiaries infected per year.

The American foulbrood infection rate in Canterbury's registered apiaries increased annually over the study period (GLM: $b=0.013, z=2.37, p<0.05$ ). The average percentage of apiaries infected was shown to have a slight fluctuation yet never surpass 2-3\%. However, the 2009-2013 period showed to have the highest infection rate when compared to previous years.

The American foulbrood infection rate in Otago's registered apiaries decreased annually over the study period (GLM: $b=-0.058, z=-9.33, p<0.001$ ). The results shown in figure 2.7 indicate that Otago may be the sole region to sustain a decreasing trend in the percentage of apiaries infected during the entirety of the study period. A sustained decrease in infection rates in Otago may be due the lower population density of the region allowing for greater distances between apiaries, therefore, limiting the ability for the disease to spread. Additionally, the implementing of control methods may have inhibited the disease's dispersal. 


\section{Seasonal trends of American foulbrood infection rates}

The seasonal trends of American foulbrood infection in New Zealand hives and apiaries were examined by plotting the average monthly reports of the disease from 1997 to 2013 (Figure 2.8). Two seasonal peaks in American foulbrood infection were observed. The major seasonal peak occurred in the spring months of September and October. A secondary, less severe, peak occurred during the autumn months of March and April.

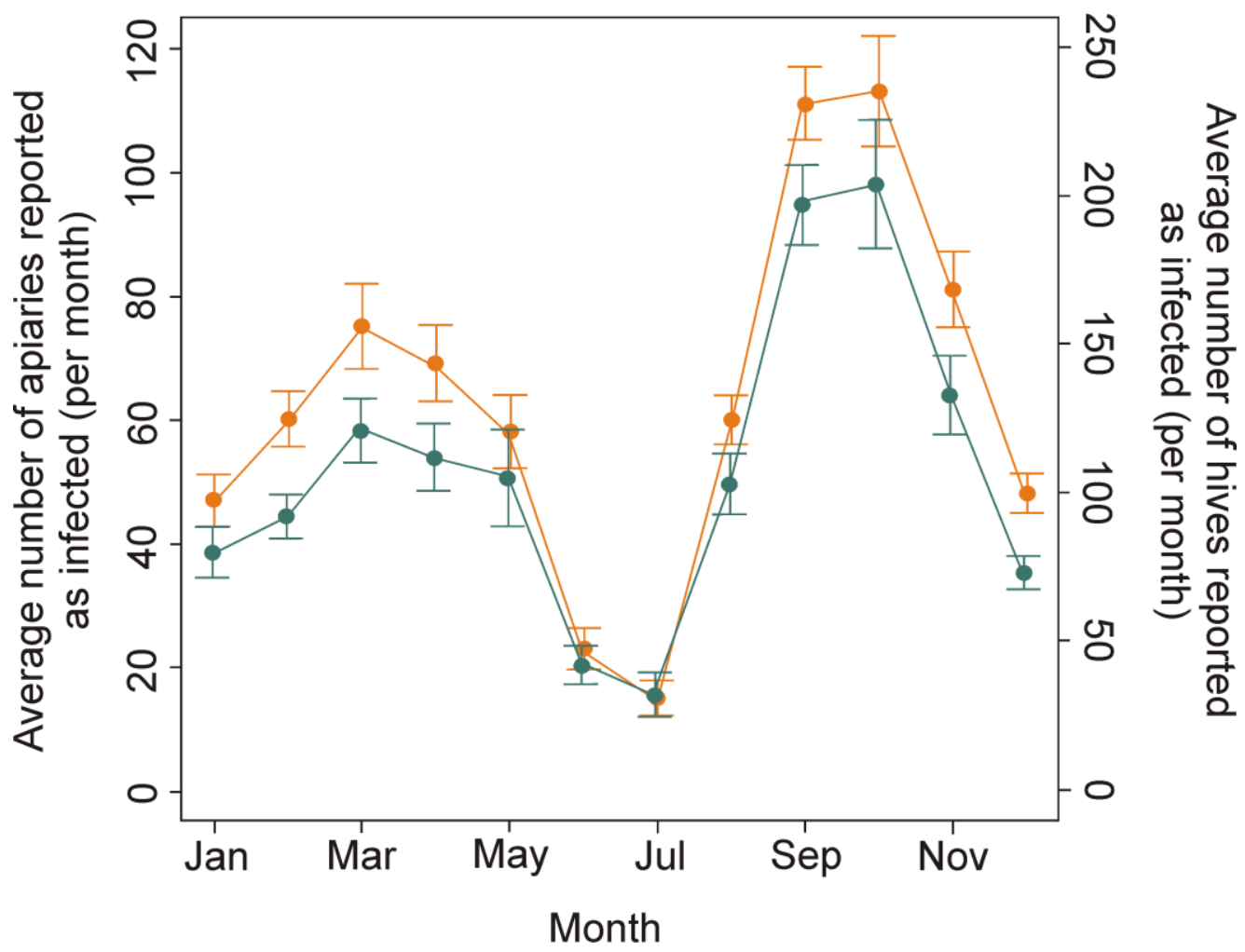

Figure 2.8: The monthly trends of American foulbrood reports. These trends represent the average number of registered hives (orange) and apiaries (green) to be reported as infected with American foulbrood per month from 1997 to 2013, with standard error bars. The graphs show two seasonal peaks during autumn and spring months. 


\section{CHAPTER THREE}

\section{Discussion}

Despite the well-established methodology, research on the occurrence and distribution of Paenibacillus larvae genetic subgroups has been predominantly focused on European and American isolates (Peters et al., 2006). ERIC I has been suggested to be primarily found in Europe and America, and ERIC II cited as being restricted to Europe (Genersch, 2010, Antunez et al., 2007). Subgroups $b$ and $B$, identified by the rep-PCR using MBO REP1 primers, are categorised into ERIC I and II respectively (Genersch \& Otten, 2003; Loncaric et al., 2009).

In this thesis, the rep-PCR method with the primer MBO REP1 was a successful tool in differentiating subgroups of $P$. larvae isolates from New Zealand field strains. The use of this method on genetic subgroups of P. larvae is a first for New Zealand. The results produced from this thesis allow for comparison with current international studies, and contributes to the increasing global knowledge on honey bee diseases. Three genetic subgroups, $b, B$, and 5 , were identified from the 33 New Zealand isolates that responded to the rep-PCR. With the identification of subgroup $b$ and $B$ in New Zealand field strains, it can be concluded that both ERIC I and ERIC II are present in New Zealand. The reporting of ERIC I and II provides the foundation to the knowledge on the potential virulence of $P$. larvae in New Zealand hives, and future control strategies. This thesis's finding of ERIC II and subgroup $\overline{5}$ in New Zealand isolates is the first reported occurrence of the genotype and subgroup outside of Europe (Peters et al., 2006). 
Of the 33 isolates, ERIC II was found to be the most frequent genotype. This result differs from European studies which reported that ERIC I was the most frequent genotype (Loncaric et al., 2009; Peters et al., 2006). The genotype ERIC II has a higher larval level virulence than ERIC I, yet ERIC I exhibits a higher colony level virulence than ERIC II (Genersch et al., 2005; Poppinga et al., 2012). The higher colony level virulence of ERIC I has been accredited to ERIC I's lower larval level virulence, which causes $P$. larvae's visual symptoms to be delayed and, consequently, 'hidden' from the nurse bee. (Genersch, 2010), resulting in the infected larvae to be capped rather than removed, allowing for increased spore production and transmission of ERIC I (Genersch, 2010).

Isolates in this study were gathered from Plant and Food Research Ltd. The samples sent to Plant and Food Research Ltd are from beekeepers' hives around New Zealand, detected with possible symptoms of $P$. larvae. Due to the delayed development of ERIC I's visual symptoms, once it is detected within the infected hive laboratory diagnosis may no longer be required as the symptoms are unambiguous and the hives are burnt. This may lead to ERIC I samples being less likely to be sent to Plant and Food Research Ltd for analysis. It is possible that ERIC II was observed as more abundant than ERIC I, as ERIC II infected hives are more ambiguous to diagnose on site. As a result ERIC II has a higher probability of being sent to Plant and Food Research Ltd for diagnosis than ERIC I samples. A potential method for examining this hypothesis would be for a randomized sampling of infected hives around New Zealand.

Another explanation is that the visual symptoms of ERIC I are hidden from beekeepers in a similar way to what has been recorded with nurse bees (Genersch, 2010). As a result ERIC II was observed as more abundant than ERIC I, as ERIC II 
symptoms are easier for the beekeeper to notice and are detected more frequently, resulting in a greater number of ERIC II samples being sent for analysis than ERIC I samples. To test this hypothesis research would need to focus on determining what I have termed the 'visual virulence' of $P$. larvae's genotypes, or the time taken for a hive infected with either ERIC I or ERIC II to display visual symptoms that are detectable in the field. Another research option is again a randomized sampling of infected hives around New Zealand.

During culturing, a high number samples (130 out of 172) failed to produce $P$. larvae colonies, even though these samples had previously been diagnosed as infected. A percentage of the isolates were from samples that had been stored at $-30^{\circ} \mathrm{C}$ for over three years. This raises some key questions: was the high level of failed colony growth a result of $P$. larvae spores within these samples not 'surviving' the long-term storage? If so, is there a relationship between the longevity of spores in long-term storage and the genotypes of the spores? This could also explain the frequency in which ERIC II occurred. Examination of the relationship between spore survival and storage time, in addition to genotypes of the stored samples would need to be conducted before these questions may be answered.

Subgroup $b$ was found to be absent from isolates gathered from Hamilton and Tauranga. Subgroup 5 was reported as absent from Blenheim isolates. Hamilton, Tauranga, and Blenheim had the lowest regional sample sizes with two isolates per region, yet all three regions had two different subgroups identified within them. The absence of subgroups $b$ or $E$ in these regions respectively could be linked to the low sample size of the study. Regions with larger samples sizes (Whangarei, Palmerston North, and Canterbury) were found to have at least one of each of the three detected genetic subgroup within their isolates. These results suggest that a greater variation of 
subgroups may occur in areas such as Blenheim. Further work with a greater sample size is needed before conclusions can be drawn on the regional variation of $P$. larvae subgroups. Previous studies have, however, recorded geographic clustering of the genetic subgroups of P. larvae (Genersch \& Otten 2003; Peters et al., 2006). Suggesting that these subgroups may be truely absent from these regions. Another aspect to consider for further research is that $P$. larvae subgroups such as ' $\beta$ ' may have gone undiagnosed in this study due to the small sample size.

Honey bees were introduced into New Zealand from Europe and America in the $19^{\text {th }}$ century. Due to the introduction of American foulbrood, the importation of honey bees into New Zealand was banned in 1927 (Donovan, 1980). Theoretically, all $P$. larvae subgroups should have been present in New Zealand prior to 1927. Nevertheless, $P$. larvae subgroups being introduced illegally or accidentally cannot be ruled out. The introduction of varroa mite (Varroa destructor) in 2000 and the Argentine ant in 1990 emphasize the ability of diseases and pests to be introduced into New Zealand, despite strict biological control at the border (Zhang, 2000; Corin et al., 2007). A more recent example of how diseases are potentially transmitted into New Zealand is seen with the attempted smuggling of multiple kilograms of pollen and honey into New Zealand from unknown origin in 2014 (Federated Farmers, 2014).

Knowledge on New Zealand's $P$. larvae genetic subgroups could aid in future risk assessment and control of American foulbrood. (Loncaric et al., 2009). As P. larvae genotypes are linked to the disease's virulence within hives, understanding the possibility of delayed visual detection and spread of the disease could influence the control methods provided to the beekeeping community. The different virulence reported in ERIC genotypes influences the time taken for an infected hive to collapse. As both ERIC I and II have been recorded in New Zealand hives, control strategies 
may wish to inform the beekeeping community that $P$. larvae can display different 'killing' times of both larvae and colonies. With the visual symptoms of the disease potentially being delayed and/or hidden within capped larvae. The introduction of new strategies, such as removing the caps off selected capped larvae to check for symptoms, may need to be considered to allow for earlier detection of the disease and to reduce the opportunities for spread. It may also prove beneficial to inform the beekeeping community that due to possible delayed visual symptoms of $P$. larvae, by the time the disease is detected there is potential for the disease to have spread to surrounding hives. More research is perhaps required before these strategies are considered. By providing the first insight on the New Zealand's P. larvae genotypes does allow for the opportunity to target management strategies to different the genotypes, and inform beekeepers of the different virulence of the disease.

Since 2004 for hives and 2006 for apiaries, New Zealand has experienced an exponential growth of registered hives and apiaries. The current trend of increasing registration numbers has surpassed previous peaks. Beekeeper registration trends have shown an incline since 2007, but this has not surpassed the previous peaks. The increase in hive and apiary registration could be linked to the increasing value of Manuka honey or through an increased awareness and accessibility to New Zealand registration laws through tools such as the Internet (MPI, 2014; Matherson \& Reid, 2011). It has also been suggested that the growth in hives numbers is attributed to the increase in urban and hobbyist beekeepers and the need for honey bees for agricultural pollination, especially since varroa mite has decimated feral hive numbers (Hanson, 2014). As beekeepers' numbers are not increasing to the extent of hives and apiaries, this might suggest that a few beekeepers are increasing their hive and apiary 
numbers; rather than an increase in multiple beekeepers with small numbers of hives and apiaries (e.g. hobbyists), as suggested.

In 1998, changes were made to New Zealand's law on American foulbrood management (Biosecurity Order, 1998). Changes to the law included the compulsory annual inspection of hives by certified inspectors, and the reporting of infected hives within seven days of diagnosis (Biosecurity Order, 1998). The objectives of AFB NPMS were strategised within the Biosecurity law. The primary objective was to decrease hive infection reports to below $0.1 \%$ by 2007 (Biosecurity Order, 1998). This thesis focused on American foulbrood data from 1994 to 2013 in four five-year periods (1994-1998; 1999-2003; 2004-2008; 2009-2013), encompassing the most recent law changes in 1998. From 1994 to 2013, American foulbrood infection rates in New Zealand's registered hives and apiaries were found to be decreasing overall. These findings are similar to those found in Goodwin's (2006) work. Results also reported that two regions, Tauranga and Otago, showed hive infection rates that were below $0.1 \%$. This occurred in both regions during years within the 2009-2013 period rather than 2007 as aimed for. Conversely, some regions were reported to have substantially higher rates of infection trends (e.g. Whangarei), or trends in infection appear to be increasing (e.g Canterbury and Palmerston North).

New Zealand's American foulbrood trends did show an increase in infection rate during 1999-2003, before a sustained decline from 2004 onwards. Three of the seven regions also showed an increase in infection rates in hives and apiaries during this period. Two of the three regions were located in the North Island: Hamilton and Tauranga, with Canterbury the sole South Island region. Whangarei also exhibited an increase in infection rates in its hive during this period, but not in its apiaries. During 
2004-2008, Palmerston North's hives and apiaries exhibited an increase in infection rates and in Blenheim's hives and apiaries in 2009-2013.

The infection rate increase that was reported could be in response to the introduction of varroa mite (Varroa destructor) into New Zealand (Zhang, 2000). Mondet et al.'s (2014) paper detailed the spread of varroa mite in New Zealand from 2001 to 2014. The year in which varroa mite was first reported within a region was the same year that the particular region expressed an increasing trend in American foulbrood infection. This was seen in Whangarei, Hamilton, Tauranga, Palmerston North, and Blenheim. Canterbury was the sole region not to display this pattern, and as varroa mite was first reported in Otago in 2013 data from Otago was not yet available for analysis. In 2001, varroa mite was reported in Whangarei, Hamilton, and Tauranga. In 2004, varroa mite was reported in Palmerston North (Mondet et al., 2014). These years fall into the five-year period in which these regions exhibited an increase trend in American foulbrood. Initial reports of varroa mite in the geographical boundaries of Blenheim were spread across four years from 2006 to 2010. The latter part of the documented varroa mite spread into Blenheim aligns with the regions 2009-2013 infection rate increase. Varroa mite was first reported in Otago in 2013 meaning it is too soon to see if American foulbrood infection rates will show a relationship with varroa mite in Otago as seen in other regions. Nevertheless, I predict that an increase in American foulbrood is likely to occur in Otago after varroa mite entry.

If the increase in American foulbrood infection rates is related to the introduction of varroa mite into the region, then the reported increases may have occurred for three reasons. 
Firstly, perhaps American foulbrood infection rates increased as attention was directed towards varroa mite, with information on and the control of American foulbrood being neglected. Evidence to support this hypothesis is seen with the New Zealand beekeepers journal failing to publish an annual American foulbrood review in 2000, the year varroa mite was introduced. Also in 2000 , the journal was mostly dedicated to publishing information on the varroa mite. The greatest American foulbrood infection rate increase trend was recorded in 1999-2003, the same time period in which varroa mite was introduction to New Zealand. Time periods post 1999-2003 had less severe increases in infection rates. This may suggest that as varroa mite spread throughout New Zealand beekeepers became more aware of its occurrence and controls for the mite, redirecting attention towards American foulbrood again.

Secondly, American foulbrood infection rates may have increased as attention towards varroa mite directed beekeepers attention toward honey bee diseases and hive health in general. Thus by proxy, American foulbrood was detected more frequently. This effect may explain the increase in American foulbrood infection rates in 19992003. This would also explain the increase in infection rates in Canterbury, as beekeepers could have been checking hives for varroa mite and detected other hive diseases while during so.

Another possible explanation for the increased infection rates recorded in 19992003 is the new laws and strategies on the American foulbrood control, implemented in 1998. This may have lead to an increase in the awareness and action by beekeepers towards American foulbrood, resulting in a raise in the disease's detection. Increasing the awareness towards American foulbrood, the implementing of laws, and the use of inspectors has been linked to the decrease in American foulbrood reports in England 
and Wales (Wilkins et al., 2007). If so, the applying of the new laws and strategies could be used to explain the increase in American foulbrood reports in Canterbury, Hamilton, Tauranga, and Whangarei, and in the New Zealand average.

Results showed a shared trend between hive and apiary infection rates, suggesting that infections occur in few hives in multiple apiaries rather then being condensed to one apiary with multiple hives. My results suggest that American foulbrood infections are 'balanced' in distribution rather then disproportionately infecting only a few apiaries heavily. This result proposes that beekeepers are noting the disease within their apiaries and are limiting the spread to other hives through fast treatment of the disease. It might also indicate that the treatment of burning hives limits the spread of the disease within an apiary. The 'balanced' distribution also suggests that the disease is spreading between apiaries, with apiaries not infected with American foulbrood coming into contact with infected hives. American foulbrood appears to be infecting hives without causing collapse sufficiently long enough to allow for the disease to spread to nearby apiaries, yet not long enough to devastate an apiary. Lindstrom et al. (2008b) found that uninfected hives within $1 \mathrm{~km}$ of infected hives could successfully become infected with American foulbrood through horizontal transmission. This demonstrates that transmission of American foulbrood can be a natural occurrence rather than being spread through beekeepers (e.g. infected equipment). Yet, as previous studies have reported that artificial transmission through a beekeeper is a variable method to spread of the disease, it cannot be ruled out (Berenyi et al., 2006; Genersch, 2008). Geographic mapping of infected hives' apiary locations could give an understanding to whether or not the disease's spread is occurring due to the proximity of infected hives to uninfected hives or through beekeeper-mediated transmission. 
American foulbrood in New Zealand appears to be decreasing, even with the number of registered hives and apiaries reported increasing. This result suggests that the control of American foulbrood is not achieved by a decreasing the honey bee population but rather by other means of control. If this trend continues, American foulbrood disease control will not have to implement new strategies aiming at population control as a method. This differs from other bacterial diseases' control methods. For example, the bacteria species Brucella causes spontaneous abortions in Yellowstone bison and cattle. The bacteria's spread was found to be reliant on the population threshold of bison; by decreasing the bison's population to below 200 the pathogen does not spread to the neighbouring cattle population (Dobson \& Meagher, 1996). Such findings on American foulbrood are beneficial to the apiculture industry as it infers that limiting transmission routes, rather than the host's population size, could be a successful method for controlling the disease.

This thesis's study period of 1994 to 2013 encompasses the implementation of the AFB NPSM strategy and the 1998 Biosecurity Order law changes to American foulbrood control in New Zealand. Temporal and geographic changes to the American foulbrood infection rates were analysed nationally and regionally. This gave insight to American foulbrood infection rates in New Zealand's hives and apiaries after the law and management changes. Though the strategy was not considered successful, as it did not achieve its main aim of New Zealand's average infection rate being lowered to below $0.1 \%$ by 2007 , nationally, New Zealand was found to have experienced a significant decline in the infection rates. Based on these results one could argue that the current AFB NPSM strategy is succeeding. Four of the seven regions were reported to be experiencing significant decline in infection rates during this study period (Hamilton, Tauranga, Blenheim, and Otago). However, three of the seven 
regions were reported to be increasing in infection rate (Whangarei, Palmerston North, and Canterbury). The reasons for increased rates may be due to misapplication of American foulbrood control methods or the transmission routes of the disease becoming more accessible within these regions. For example, apiaries may be within a closer proximity to each other in regions experiencing an increase in infection rates compared with regions that are not. Another possibility for increasing infection rates could be the presence of unregistered hives and apiaries in these regions, as unregistered hives and apiaries have been suggested to help facilitate the persistence and spread of the honey bee diseases (Sanson, 2007). An additional explanation is there may be a higher number of hobbyist within these regions, as hobbyist have been linked to aiding in the dispersing of other devastating honey bee diseases such as Nosema ceranae (Klee et al., 2007). Supplementary research will need to be conducted within these regions to further understand reasons for the increasing infection rate.

Seasonality is a major driving force of infectious diseases' dynamics (Stone et al., 2007). The analysis of monthly American foulbrood infection reports in New Zealand showed a primary peak in the number of hives and apiaries infected in September and October, and a secondary peak in March and April. These two peaks fall into New Zealand's spring and autumn seasons respectively. During September and October, beekeepers are recommended to check brood frames for American foulbrood (Matherson \& Reid, 2011). If not certified themselves, beekeepers must under law employ a certified inspector to inspect their hives during August to November each year (Biosecurity Order, 1998). Beekeepers are also recommended to check hives for American foulbrood in April, in preparation for wintering hives (Matherson \& Reid, 2011). If the peaks in American foulbrood reports are in response to beekeepers 
implementing American foulbrood control and recommendations, it may suggest that the most recent long-term AFB NPSM strategies are successful. Beekeepers are also recommended to check hives in November and February, yet there is no peak in American foulbrood reports during these months (Matherson \& Reid, 2011). Moreover, in March there is no recommendation to inspect hives for American foulbrood, yet a peak is recorded (Matherson \& Reid, 2011). This suggests peaks in reports must not purely be based on beekeepers inspecting hives during recommended months.

The peaks of infection reports could instead or additionally be a result of American foulbrood unambiguously exhibiting visual symptoms, rather then beekeepers' diligence to laws. One possible explanation could be the temporal dynamics of the diseases' genotypes in hives, with the seasonal peaks in infection reports a response to the genotypes present in a hive. For example, hive robbing, or the robbing of weaker hives by stronger ones, occurs predominately in late summer and occasionally in spring and is indicated to be a major transmission route for American foulbrood (Lindstrom et al., 2008b). This begs the question of whether the peaks in infection reports during the spring months of September and October could be due to the presence of ERIC II, with its high larval level virulence causing the display of visual symptoms soon after robbing has occurred? Are the peaks in the autumn months of March and April a result of the late summer hive robbing transmitting ERIC I into the hive, meaning visual symptoms are delayed until autumn? Additional research would be needed to answer these questions. Such research could be as the previously mentioned 'visual virulence' where the time taken for a genotype to display visually diagnosable symptoms is recorded. Another 
research option is a survey which asks beekeepers their rational behind inspecting hives for American foulbrood, if any.

In summary, by providing the most recent and comprehensive epidemiological study of American foulbrood, this thesis provides the 'next step' in the study of the disease in New Zealand. The global distribution and devastating effect of the disease on honey bee colonies had led to international studies on the genotypes and distribution of American foulbrood. The genetic analysis conducted in this thesis is a first for New Zealand. Through using a well-established methodology, New Zealand can now contribute and draw information from the ever-increasing international knowledge on American foulbrood. Understanding the genetic subgroups and genotypes present in New Zealand allows the opportunity for future strategies to consider the different virulence of the disease's genotypes, and the repercussions this may have in regards to the diseases' spread and diagnosis. The statistical analysis provides an up to date insight to American foulbrood infection rates in registered hives and apiaries both nationally and regionally. The mapping of 20 years of American foulbrood spread and distribution shows the temporal and geographic dynamics of the disease and also encompasses the most recent legislative changes on the disease's control. By understanding the variation between regions, strategies on American foulbrood control can become more accurate and aid in increasing the efficiency of the management strategies of the disease. It is hoped that the findings in this thesis are able to contribute to both the scientific and beekeeping community. 


\section{Bibliography}

Alippi, A.M., Lopez, A.C., Aguilar, O.M. (2002). Differentiation of Paenibacillus larvae subsp. Larvae, the cause of American foulbrood of honeybees, by using PCR and restriction fragment analysis of genes encoding 16s rRNA. Applied and Environmental Microbiology 68(7): 3655-3660.

Alippi A.M., \& Reynaldi, F.J. (2006). Inhibition of the growth of Paenibacillus larvae, the causal agent of American foulbrood of honeybees by selected strains of aerobic spore-forming bacteria isolated from apiarian sources. Journal of Invertebrate Pathology 91: 141-146.

Alippi A.M., Reynald, F.J., Lopez, A.C., De Giusti, M.R., Aguilar, O.M. (2004). Molecular epidemiology of Paenibacillus larvae larvae and incidence of American foulbrood in Argentinean honeys from Buenos Aires province. Journal of Apicultural Research 43(3): 131-139.

Amdam, G.V., Norberg, K., Fondrk, M.K., Page Jr., R.E. (2004). Reproductive ground plan may mediate colony-level selection effects on individual foraging behavior in honey bees. PNAS 101(31): 11350-11355.

Antunez, K., Piccini, C., Castro-Sowinski, S., Rosado, A.S., Seldin, L., Zunino, P. (2007). Phenotypic and genotypic characterization of Paenibacillus larvae isolates. Veterinary Microbiolgy 124: 178-183.

Arena, C. (2010). Urban beekeeping: what is all the buzz about? Retrieved from http://law.psu.edu/_file/aglaw/Urban_Beekeeping_Christine_Arena.pdf 
Bakonyi, T., Derakhshifar, I., Grabensteiner, E., Nowotny, N. (2003). Development and evaluation of PCR assays for the detection of Paenibacillus larvae in honey samples: comparison with isolation and biochemical characterization. Applied and Environmental Microbiology 69(3): 1504-1510.

Becher, M.A., Osborne, J.L., Thorbek, P., Kennedy, P.J., Grimm, V. (2013). Towards a systems approach for understanding honeybee decline: a stocktaking and synthesis of existing models. Journal of Applied Ecology 50: $868-880$

Berenyi, O., Bakonyi, T., Derakhshifar, I., Kogleberger, H., Nowotny, N. (2006). Occurrence of six honey bee viruses in diseases Austrian apiaries. Applied and Environmental Microbiology 72(4): 2414-2420.

Biosecurity (National American foulbrood pest management strategy) Order 1998, SR 1998/260 s.68, New Zealand.

Butz Huryn, V.M. (1997). Ecological impacts of introduced honey bees. The Quarterly Review of Biology 72(3): 275-297.

Calderone, N. (2012a). Insect pollinated crops, insect pollinators and US agriculture: trend analysis of aggregate data for the period 1992-2009. PLoS One 7(5): 128.

Calderone, N. (2012b). The contribution of insect pollinators to U.S. agriculture. Bee Culture 140(12): 32-38.

Campbell, D.R. (2008). Pollinators shifts and the origin and loss of plant species. Annals of the Missouri Botanical Gardens 95(2): 264-274. 
Chen, Y., Zhao, Y., Hammond, J., Hsu, H., Evans, J., Feldlaufer, M. (2004). Multiple virus infections in the honey bee and genome divergence of honey bee viruses. Journal of Invertebrate Pathology 87: 84-93.

Chittka, L., \& Menzel, R. (1992). The evolutionary adaptation of flower colours and the insect pollinators' colour vision. Journal of Comparative Physiology A 171: 171-181.

Corin, S. E., Lester, P. J., Abbott, K.L., Ritchie, P.A. (2007). Inferring historical introduction pathways with mitochondrial DNA: the case of introduced Argentine ants (Linepithema humile) into New Zealand. Diversity and Distributions 13:151-518.

Currie, R.W. \& Tahmasbi, G.H. (2008). The ability of high- and low- grooming lines of honey bees to remove the parasitic mite Varroa destructor is affected by environmental conditions. Canadian Journal of Zoology 86: 1059-1067.

D’Alessandro, B., Antunez, K., Piccini, C., Zunino, P. (2007). DNA extraction and PCR detection of Paenibacillus larvae spores from naturally contaminated honey and bees using spore-decoating and freeze-thawing techniques. World Journal of Microbiology and Biotechnology 23: 593-597.

Danka, R.G., de Guzman, L.I., Rinderer, T.E., Sylvester, H.A., Wagener, C.M., Bourgeois, A.L., Harris, J.W., Villa, J.D. (2012). Functionality of Varroaresistant honey bee (Hymenoptera: Apidae) when used in migratory beekeeping for crop pollination. Journal of Economic Entomology 105(2): 313-321. 
Dobson, A. \& Meagher, M. (1996). The population dynamics of Brucellosis in the Yellowstone National Park. Ecology 77(4):1026-1036.

Dobson, A. \& Carper, R. (1992). Global warming and potential change in hostparasite and disease-vector relationships. Global Warming and Biodiversity. New Haven, CT: Yale University Press.

Donovan, B.J. (1980). Interactions between native and introduced bees in New Zealand. New Zealand Journal of Ecology 3: 104-116.

Evans, J.D., \& Schwarz, R.S. (2011). Bees brought to their knees: microbes affecting honey bee health. Trends in Microbiology 19(12): 614-620.

Evans, J.D., \& Spivak, M. (2010). Socialized medicine: individual and communal disease barriers in honey bees. Journal of Invertebrate Pathology 103: S67S72.

Federated Farmers. (2014). Smuggling honey into New Zealand isn't sweet [Press release]. Retrieved from http://www.fedfarm.org.nz/publications/mediareleases/article.asp?id=1904\#.VHvRsGSUfdI.

Forsgren, E. (2010). European foulbrood in honey bees. Journal of Invertebrate Pathology 103: S5-S9.

Forsgren, E., Stevanovic, J., Fries, I. (2008). Variability in germination and in temperature and storage resistance among Paenibacillus larvae genotypes. Veterinary Microbiology 129: 342-349. 
Genersch, E. (2008). Paenibacillus larve and American foulbrood - long since known and still surprising. Journal of Consumer Protection and Food Safety 3: $429-434$

Genersch, E. (2010a). American foulbrood in honeybees and its causative agent, Paenibacillus larvae. Journal of Invertebrate Pathology 103: S10-S19.

Genersch, E. (2010b). Honey bee pathology: current threats to honey bee and beekeeping. Applied Microbiology and Biotechnology 87, 87-97.

Genersch, E., \& Otten, C. (2003). The use of repetitive element PCR fingerprinting (rep-PCR) for genetic subtyping of German field isolates of Paenibacillus larvae subsp. larvae. Apidologie 34: 195-206.

Genersch, E., Ashiralieva, A., \& Fries, I. (2005). Strain- and genotype-specific differences in virulence of Paenibacillus larvae subsp. larvae, a bacterial pathogen causing American foulbrood disease in honeybees. Applies and Environmental Microbiology 71(11): 7551-7555.

Genersch, E., Evans, J.D., Fries, I. (2009). Honey bee disease overview. Jounral of Invertebrate Pathology 103: S2-S4.

Genersch, E., Forsgren, E., Pentikaninen, J., Ashiralieva, A., Rauch, S., Kilwinski, J., \& Fries, I. (2006). Reclassification of Paenibacillus larvae subsp. pulvifaciens and Paenibacillus larvae subsp. larvae as Paenibacillus larvae without subspecies differentiation. International Journal of Systematic and Evolutionary Microbiology 56: 501-511.

Goodwin, M. (2006). Elimination of America foulbrood disease without the use of drugs: A practical manual for beekeepers. New Zealand: ISBN. 
Goodwin, R.M., Houten, A.T., Perry, J.H. (1994). Incidence of American foulbrood infections in feral honey bee colonies in New Zealand. New Zealand Journal of Zoology 21: 285-287.

Goodwin, M., \& Van Eaton, C. (2001). Control of Varroa: A guide for New Zealand Beekeepers. Retrieved from New Zealand government biosecurity website: http://www.biosecurity.govt.nz/files/pests/varroa/control-of-varroa-guide.pdf

de Graaf, D.C., Alippi, A.M., Antúnez, K., Aronstein, K.A., Budge, G., De Koker, D., De Smet, L., Dingman, G.W., Evans, J.D., Foster, L.J., Funfhaus, A., Garcia-Gonzalez, E., Gregorc, A., Human, H., Murray, K.D., Nguyen, B.K., Poppinga, L., Spivak, M., vanEngelsdorp, D., Wilkins, S., Genersch, E. (2013). Standard methods to for American foulbrood research. Journal of Apicultural Research 52(1), 1-27.

de Graaf, D.C., Alippi, A.M., Brown, M., Evans, J.D., Feldlaufer, M., Gregorc, A., Hornitzky, M., Pernal, S.F., Schuch, D.M.T., Titera, D., Tomkies, V., Ritter, W. (2006). Diagnosis of American foulbrood in honey bees: a synthesis and proposed analytical protocols. Applied Microbiology 43: 583-590.

Guzman-Novoa, E., \& Page, R.E. (1999). Selective breeding of honey bees (Hymenoptera: Apidae) in Africanised areas. Journal of Economic Entomology 92(3): 521-525.

Hanson, N. (2014). Beekeepers' lives looking sweet. Retrieved from http://www.nzherald.co.nz/hawkes-baytoday/rural/news/article.cfm?c_id=1503457\&objectid=11277371. 
Huang, Z.Y. \& Robinson, G.E. (1996). Regulation of honey bee division of labor by colony age demography. Behaviour Ecology and Sociobiology 39: 147-158.

Ibrahim, A., Reuter, G.S., Spivak, M. (2007). Field trial of honey bee colonies bred for mechanisms of resistance against Varroa destructor. Apidologies 38: 6776.

Klee, J., Besana, A.M., Genersch, E., Gisder, S., Nanetti, A., Tam, D.Q., Chinh, T.X., Puerta, F., Ruz, J.M., Kryger, P., Message, D., Hatjina, F., Korpela, S., Fries, I., Paxton, R.J. (2007). Widespread dispersal of the microsporidian Nosema ceranae, an emergent pathogen of the western honey bee, Apis mellifera. Journal of Invertebrate Pathology 98: 1-10.

Klein, A.M., Vaissiere, B.E., Cane, J.H., Steffan-Dewenter, I., Cunningham, S.A., Kremen, C. Tscharntke, T. (2007). Importance of pollinators in changing landscapes for world crops. Proceedings of the Royal Society 264: 303-313.

Le Conte, Y. \& Navajas, M. (2008). Climate change: impact on honey bee populations and diseases. Scientific and Technical Review of the Office International des Epizooties 27(2): 499-510.

Lindstrom, A. (2008). Distribution of Paenibacillus larvae spores among adult honey bee (Apis mellifera) and the relationship with clinical symptoms of American foulbrood. Microbial Ecology 56: 253-259.

Lindstrom, A. \& Fries, I. (2005). Sampling of adult bee for detection of American foulbrood (Paenibacillus larvae subsp. larvae) spores in honey bee (Apis mellifera) colonies. Journal of Apicultural Research 44(2): 82-86. 
Lindstrom, A., Korpela, S., Fries, I. (2008a). The distribution of Paenibacillus larvae spores in adult bees and honey and larval mortality, following the addition of American foulbrood disease brood or spore-contaminated honey in honey bee (Apis mellifera) colonies. Journal of Invertebrate Pathology 99: 8286.

Lindstrom, A., Korpela, S., Fries, I. (2008b). Horizontal transmission of Paenibacillus larvae spores between honey bee (Apis mellifera) colonies through robbing. Apidologie 39: 515-522.

Loncaric, I., Derakhshifar, I., Oberlerchner, J.T., Koglberger, H., Moosbeckhofer, R. (2009). Genetic diversity among isolates of Paenibacillus larvae from Austria. Journal of Invertebrate Pathology 100: 44-46.

MAF. (2008). Report on the American foulbrood National Pest Management Strategy. (Paper No: 2008/07). Wellington, New Zealand: Ministry of Agriculture and Forestry, Biosecurity New Zealand.

Malone, L.A., Giacon, H.A., Newton, M.R. (1995). Comparision of the repsonses of some New Zealand and Australian honey bee (Apis mellifera L) to Nosema apis Z. Apidologie 26: 495-502.

Matherson, A., \& Reid, M. (2011). Practical beekeeping in New Zealand. Auckland, New Zealand: Exisle Publishing Limited.

Ministry of Primary Industries (MPI). (2014). High-performance Manuka plantations. Retrieved from http://www.mpi.govt.nz/agriculture/fundingprogrammes/primary-growth-partnership/high-performance-manukaplantations 
Mondet, F., de Miranda, J.R., Kretzschmar, A., Le Conte, Y., Mercer, A.R. (2014). On the Front Line: Quantitative Virus Dynamics in Honeybee (Apis mellifera L.) Colonies along a New Expansion Front of the Parasite Varroa destructor. PLOS pathogens 10(8): 1-15.

National Beekeepers' Association of New Zealand (NBA). (2011). Interesting Facts. Retrieved from http://nba.org.nz/interesting-facts.

Neumann, P. \& Carreck, N.L. (2010). Honey bee colony losses. Journal of Apicultural Research 49(1): 1-6.

Palmer-Jones, T. (1964). Disease of honey bees in New Zealand. New Zealand Entomologist 3: 41-44.

Peters, M., Kilwinski, J., Beringhoff, A., Reckling, D., Genersch, E. (2006). American foulbrood of the honey bee: occurrence and distribution of different genotypes of Paenibacillus larvae in the administrative district of Arnsberg (North Rhine-Westphalia). Journal of Veterinary Medicine Series B 53: 100104.

Pinto, A.D., Novello, L., Terio, V., Tantillo, G. (2011). ERIC-PCR genotyping of Paenibacillus larvae in Southern Italian honey and brood comb. Current Microbiology 64: 416-419.

Poppinga, L., Janesch, B., Funfhaus, A., Sekot, G., Garcia-Gonzalez, E., Hertlein, G., Hedtke, K., Schaffer, C., Genersch, E. (2012). Identification and functional analysis of the S-layer protein SplA of Paenibacillus larvae, the causative agent of American foulbrood of honey bees. PLoS Pathogens 8(5): 1-13. 
Potts, S.G., Biesmeijer, J.C., Kremen, C., Neumann, P., Schweiger, O., Kunin, W.E. (2010). Global pollinator declines: trends, impacts and drivers. Trends in Ecology and Evolution 25(6): 345-353.

Rinderer, T.E., De Guzman, L.I., Frake, A.M., Tarver, M.R., Khongphinitbunjong, K. (2014). An evaluation of the associations of parameters related to the fall of Varroa destructor (Acari: Varroidae) from commercial honey bee (Hymenoptera: Apidae) colonies as tools for selective breeding for mite resistance. Journal of Economic Entomology 107(2): 516-522.

Runckel, C., Flenniken, M.L., Engel, J.C., Ruby, J.G., Ganem, D., Andino, R., DeRisi, J.L. (2011). Temporal analysis of the honey bee microbiome reveals four novel viruses and seasonal prevalence of known viruses, Nosema, and Crithidia. PLoSOne 6(6): 1-18

Ryba, S., Kindlmann, P., Titera, D., Haklova, M., Stopka, P. (2012). A new low cost procedure for detecting nucleic acids in low-incidence samples: a case study of detecting spores Paenibacillus larvae from bee debris. Journal of Economic Entomology 105(5): 1487-1491.

Sammataro, D., Gerson, U., Needham, G. (2000). Parasitic mites of honey bees: life history, implications, and impact. Annual Review of Entomology 45: 519-548.

Stone, L., Olinky, R., Huppert, A. (2007). Seasonal dynamics of recurrent epidemics. Nature 446: 533-536.

Sanson, R.L. (2007). Simulation modelling as a tool for evaluating surveillance programmes for the detection of the Asian honey bee mite (Varroa destructor) 
in the South Island of New Zealand. New Zealand Veterinary Journals 55(6):273-279.

Todd, J.H., De Miranda, J.R., Ball, B.V. (2007). Incidence and molecular characterization of viruses found in dying New Zealand honey bee (Apis mellifera) colonies infested with Varroa destructor. Apidologie 38: 354-367.

vanEnglesdorp, D., \& Meixner, M.D. (2010). A historical review of managed honey bee populations in Europe and the United States and the factors that may affect them. Journal of Invertebrate Pathology 103: S80-S95.

Vogel, F.W. (1871). The principles of bee breeding. The American Naturalist 5(1): $17-24$

Winston, M.L. (1987). The biology of the honey bee. Cambridge, United States: Harvard University Press.

Wilkins, S., Brown, M.A., Cuthbertson, A.G.S. (2007). The incidence of honey bee pests and disease in England and Wales. Pest Management Science 63:10621068.

Yoshiyama, M., \& Kimura, K. (2009). Bacteria in the gut of Japanese honeybee, Apis cerana japonica and their antagonistic effect against Paenibacillus larvae, the causal agent of American foulbrood. Journal of Invertebrate Pathology 102: 91-96.

Zhang, Z-Q. (2000). Notes on Varroa destructor (Acari: Varroidae) parasitic on honey bees in New Zealand. Systematic and Applied Acarology Special Publications 5: 9-14. 


\section{Appendix}

\section{Appendix A: Permit}

Below is the permit given for this thesis to keep American foulbrood material within Victoria University of Wellington PC2 laboratories, for research, education, and training purposes.

THE MANAGLMENT AGENC:Y NATIONAL AMERICAN FOUULROOOD PEST MANAGEMENT PLAN

6 September 2013

Prefessor Pril Lester

$045660773-0274715701$ PO Box 44282, Lower Hutt 5040 ibaynesăihug.cons wwrw.afto.oxg.nz

bical Sciences:

Victoria Unive sity of Wellingtón

Pellincton $\$ 14$

Deur Pril

Re: Exemptions for Research, Education and Training - Pursuant to the Bfosecurfty (National American foutbrood Pest Management Plart) Order 199s: Clause 30;

PERMIT TO KEEP AFB MATERIAL FOR EDUCATION, RESEARCH AND TRAINING PURPOSES

zu-ther to yeur rec uest to store trames ar Ath 17 a freezer to be used for t-dirirg clated suncses.

The A.TB Ma lagement. Age nry may, hy ratice in writing, exerr f: eny person toom the cbliçarions in cla use 28, the prohibilion in Clause $>4$, ar the prohintior in clause 31 , for the purpobe of racearch, ediccarticn, $c$

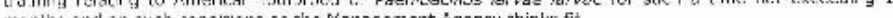

In Ine with the rrovisisns of the snsecurty (Natioral Arncriten Cud L voul Pest Management Srrategy)

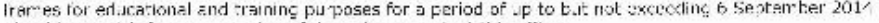
shauld you wist fo: an extension of time please centact this offic:

Conditions:

1. Storage of metera: All ACB irlecled raod fames and/or material must be wapped in

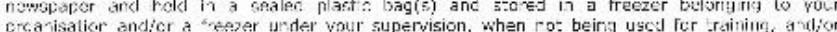
prlumatinา parpasos.

2. Siturity and non-exposula of I-fected thond frames The A.FB irfected troud trames and/0

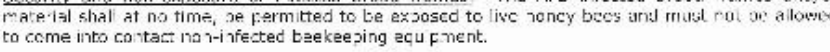

3. Labelling of Infereed Naterial: All intectud mbtericl is tu be clearly mareed with the ablyes arion

Shou d you wish to $\mathrm{y}$ scuss the conditicns as set out above p case do not her tate to e nal me ard if ne:essary I wil cal you.

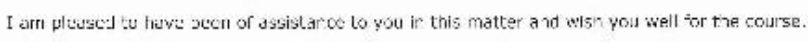

You's sir verely

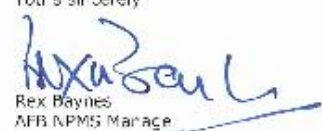

Copy: Frans Laes 